\title{
الالالات الفنية للتعبير عن عملية الخِصاء من خلال تصوير أتيس وأتباع كيبيلي في العصر الروماني
}

\section{The Artistic Connotations of Expressing the Castration Process Through the Depiction of Attis and the Followers of Cebele in the Roman Era هبه فاروق النحاس}

مدرس بقسم الآثار بكلية الآداب جامعة طنطا

\section{Heba Farouk El- Nahas}

Lecture of Greek and Roman Archaeology, Department of Archaeology Faculty of Arts, Tanta University heba alnahas@yahoo.com

يمنحنا الفن الروماني العديد من النماذج لأعمال تعكس الاختلافات الجنسية بين رعايا الإمبراطورية، حيث لم يكن فنان

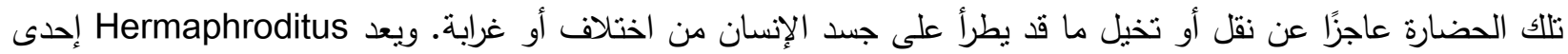
الثخصيات التي نتميز بالغوض الجنسي في الأساطير اليونانية والرومانية. إنه ابن أفروديت وهرميس لكنه نتج عن الندان اندماج مباشر بين جسديهما فصار شابًا له شكل أنثى وأعضاء ذكر. ولعل هذه الأسطورة نشأت كمحاولة لتفسير إحدى أبرز ظواهر الاختلاف الجنسي وهي التخنت. - أما المواطن الروماني فكان برى في التخنت تعارضيًا مع الأعراف الأخلاقية المعيارية

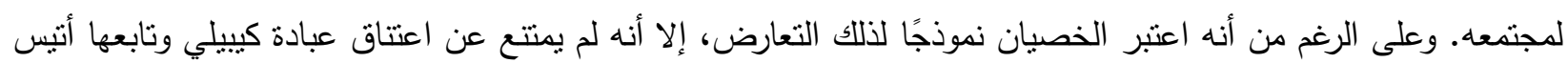

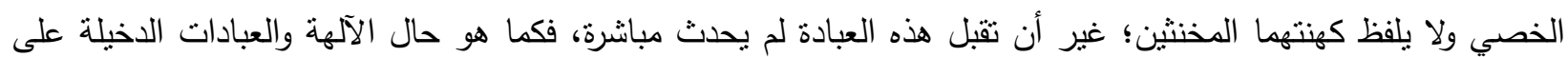

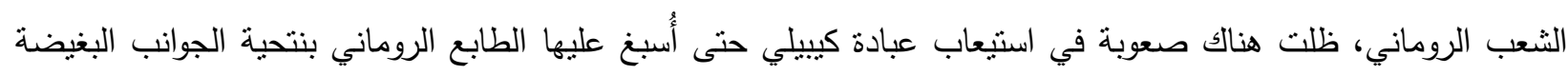

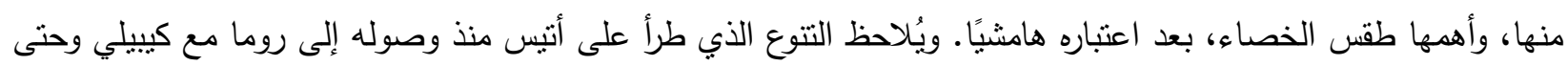

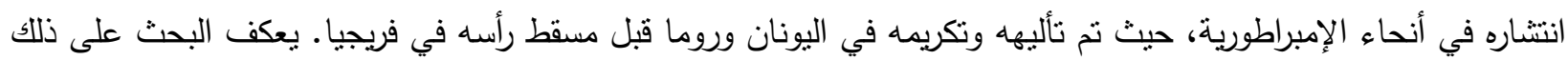

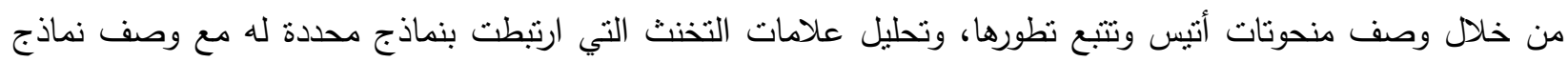
للأثباع وقادتهم الذين تتوفر دلائل صريحة على صفاتهم أو يمكن استتناجها من علامات ومخصصات كيبيلي. كما يستتتج

$$
\begin{aligned}
& \text { البحث كيفية تعبير الفنان الروماني عن مفهوم الخصاء. } \\
& \text { الكلمات الدالة: كيبيلي؛ أتيس؛ الخصاء. }
\end{aligned}
$$

\section{Abstract:}

Roman art provides us with numerous works that reflect sexual differences within the empire. In the myth of Hermaphroditus, for example - a child of Aphrodite and Hermes who embodies sexual ambiguity - was a young man with male genitals who nonetheless looked female. The Roman citizen saw gender fluidity as a breach of ethical and social criteria, and yet accepted the cult of Cybele and her follower Attis. This could only occurrence the cult had been modified and its offensive aspect - namely, the castration rite - removed. We can trace the changes that beset Attis after he entered Rome, how he was apotheosized and honored in Greece and Rome even before his birthplace, Phrygia, through the images produced of him and an analysis of specific examples of these as well as tracing the concept of castration in Roman art.

Keywords: Cybele, Attis , Castration. 
عبّر الفنان الروماني على مدى تاريخ الإمبراطورية عن الاختلافات الجنسية التي عاصرها مهما بدت

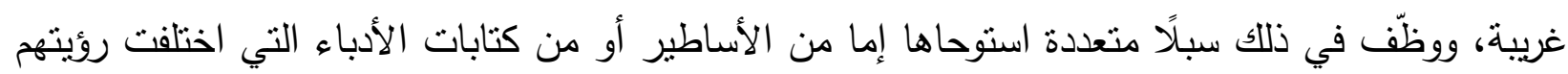

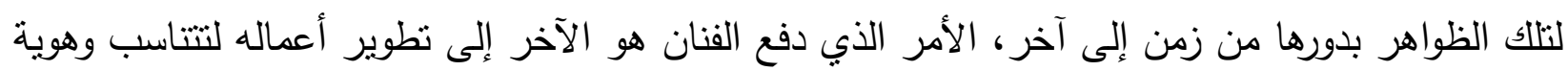

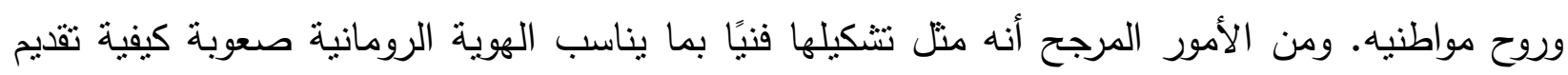
أنتس وأنباع كيبيلي من الخصيان لمواطن نفر منهم لدى دخولهم روما ولم يتقبلهم حتى نهاية الفترة الإمبراطورية.

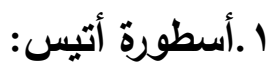

في أسطورته الليدية، يذكر هيرودت (القرن الخامس قبل الميلاد) أن أتبس Attis كان ابن الملك الليدي كروسوس Croesus. وقد ظهرت نبوءة بموته فحاول كروسوس أن بحميه بكل الطرق الممكنة ومنها

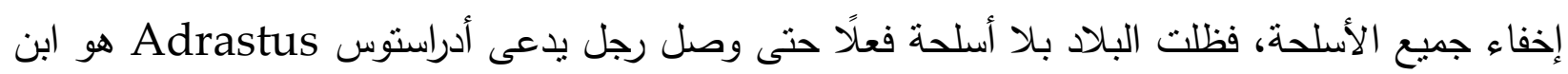

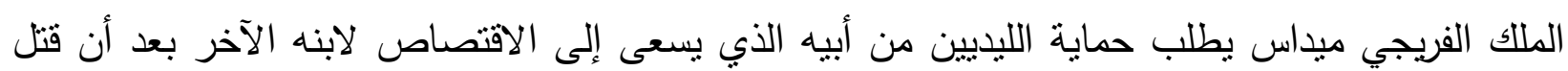

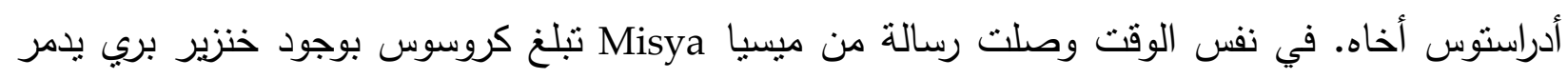

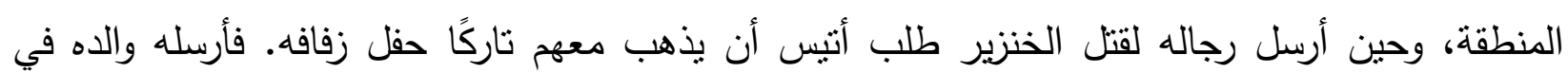

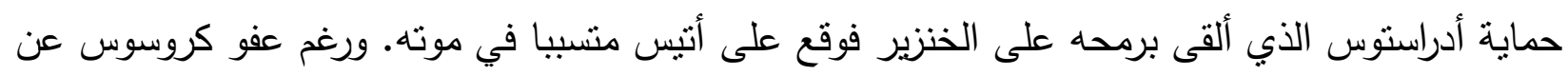

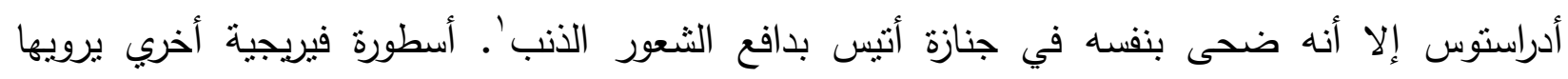
بوسانياس Pausanias (القرن الثاني الميلادي) تذهب إلى أن أتنيس هو نفسه ابن الملك الفيريجي، انتقل

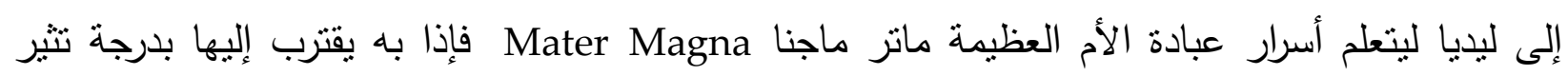

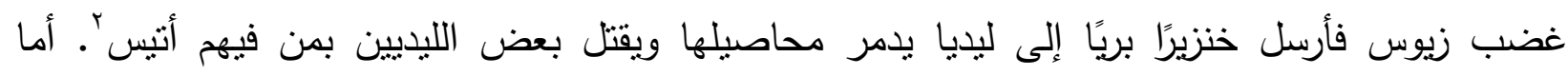

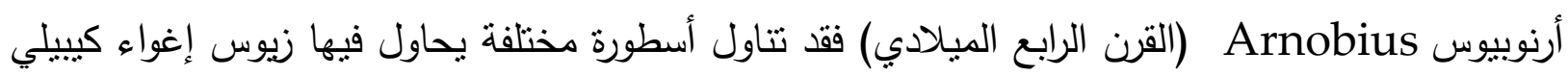

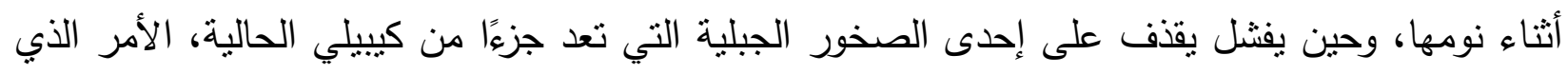

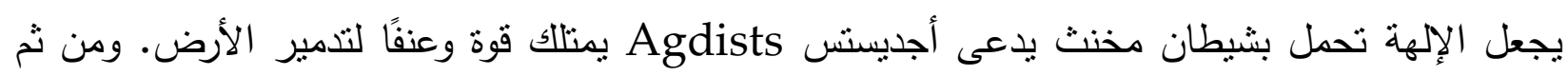
يستخدم الإله ليير Liber (إله الكرم والنبيذ) الخديعة فينتظر حتى ينام أجديسنس مخمورًا ويربط قضيبه

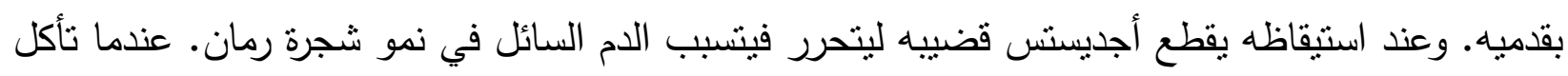

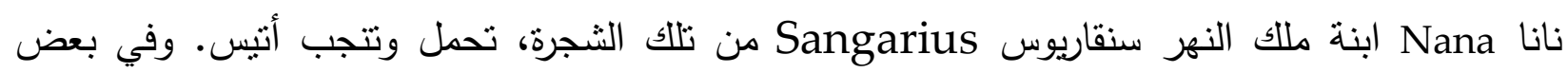
الروايات تضع نانا أنيس في حماية كيبيلي خوفًا من والدها، فيعيش في الغابة على حليب الماعز حتى لئى

1 Herodotus, translation by A. D. GodLEY, Harvard University Press; London: W. HeInEMANN, 1920-25. Book I: 34-45.

2 Pausanias, Descriptions of Greece, Translated by Jones, W. H. S. \& OMEROD, H. A, Cambridge, MA, Harvard University Press; London, William Heinemann Ltd. 1918.vol VII, 7-13.

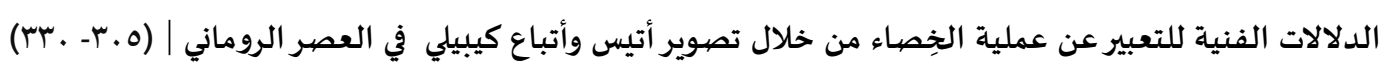


يصبح شابًا ويرتبط بأجديستس رفيقه في الصيد. يكون أجديستس على موعد للزواج من ابنة الملك الفيرجي ميداس Midas مع ذلك، ويوم زفافه يرفع كل من كيبيلي وأجديستيس أسوار المدينة فيصاب الحضور بمن فيهم أتيس بالجنون. يندفع أثيس إلى الغابة وفي حالة جنونه يخصي نفسه وينزف حتى يموت راقدًا تحت شجرة الصنوبر • في لحظة ندم لاحقة، تجمع كيبيلي أعضاءه وتتوسل إلى زيوس أن يعيده إلى الحياة، فيصعد إلى السماء دون أن يتعفن جسدهّاء. r r عبادة أتيس ودوره في عبادة كيبيلي:

كما نرى تعددت أساطير هذا المعتقد؛، ومع أنها تختلف في بعض تقاصيلها إلا أنها تُجمع على وصف الإلهة كيبيلي والقرين أتيس. تعمل أساطير كيبيلي على شرح هوية العبادة، وعلى الرغم من ذلك فهي تدور حول شخصية أتيس التي تتخذ أثكالًا وأدوارًا مختلفة في ثقافات مختلفة: حبيب كيبيلي، أو شاب يعتمد مصيره عليها. وبالتالي فهو على القدر نفسه من الأهمية لفهم مضمون الطقوس المرتبطة بالعبادة واتخاذ كهنة كيبيلي منه قدوة لهم في تقرّبهم إلى الآلهةٌْ مع ذلك لم يُعرّف أتيس بأنه إله قبل عصر الإمبراطورية الرومانية؛ وبعبارة أخرى، كُرّم أتيس كإله للأكومة والطبيعة في اليونان وروما أولاً ثم في موطنه فريجيا ثانيًا. ' ويعد أقدم تصوير عُرف لأتيس - يرجع تاريخه إلى منتصف القرن الرابع قبل الميلاد - Phrygia هو نقش نذري على معبد تذكاري صغير naiskos تم العثور عليه في بيرايوس Piraeus في اليونان، كرسته لأجديستس وأتنيس امرأة تهديه إلى طفلها. يظهر أجديستس في ذلك النقش واقفاً إلى اليسار ، وذراعه اليمنى ممدودة بإبريق لأثتيس الجالس على صخرة في مواجهة الإلهة بمد يده اليمنى لالتقاط شيء وهو برتدي túnica ثوبه الثرقي الذي سيصبح من سماته المميزة فيما بعد، والمكون من سترة بأكمام طوبلة

3 ARnOBIUS, Adversus Nationes, Translated by BRYCE, A, H. T \& T. Clark 1871, vol V, 9-17.

" للمزيد عن كيبيلي انظر : محمد حسن لازم، "الإلهة كيبيلي في الأسطورة والفن اليوناني والروماني"، ماجستير في الآداب في

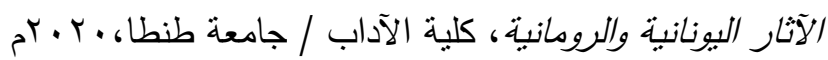

- KNAUER, ElfRIED R.:“" The Queen Mother of the West: A Study of the Influence of Western Prototypes on the Iconography of the Taoist Deity", In: Contact and Exchange in the Ancient World, University of Hawai'i Press. 2006.

${ }^{5}$ LANCELlotTI, M.G., Attis: Between Myth and History: King, Priest, and God, Brill 2002, 21.

${ }^{6}$ Roller, E.:«Attis on Greek Votive Monuments; Greek God or Phrygian?», Hesperia: 63, №. 2, 1994,. BorgeAud, P. , La Mère des Dieux. De Cybèle à la Vierge Marie, Paris, 1996. 59.

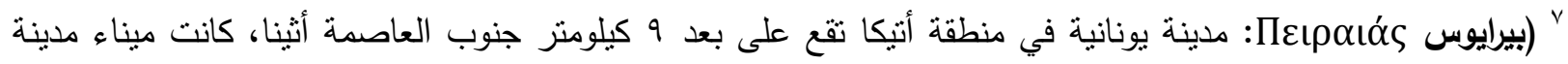

أثنينا القديمة)

- WARnER, R; FInAL, M., History of the Peloponnesian War, Penguin, 197.

^ تميزت بعض الأزياء البارثية بياقة رقبة على شكل حرف V، لا تصل أبدًا إلى أسفل الحزام عند الخصر أو الوركين. ظهرت تللك الياقة لسترة رجل في أحد رسومات دورا أوربوس Dura-Europos؛ وهو طراز فريد من نوعه في الإمبراطورية البارثية، لكنه نموذجي لبعض الثعوب الإيرانية الثمالية في ذللك الوقت (

Alans, S. \& SARMatianS, Y. ,Some Notes on Parthian Costume Studies, Parthica, 15, 2013, 117-125. 
manicata anaxyrides. يرتدي كذلك حذاء مدببًا وقبعة فريجية على رأسه. ويحمل في يده اليسرى آلته الموسيقية التي تشبه الفلوت "سيرينكس" 'syrinx ، بينما ترنكز عصا الراعي على الصخرة التي يجلس فوقها مجسًّا بذللك صورة الراعي الفريجي أو الثرقي." في روما اسثقبلت شخصية أجديسنس بالتزامن مع تحول كيبيلي إلى إلهة رسمية كماتر ماجنا Mater Magna سنة ع • ب قبل الميلاد. وكان نتيجة ذلك أيضًا أن يلتحق بالسياقات الجنائزية كAttis Tristis الراعي الثاب الحزين الذي يرافق المتوفى 'ا . ويظهر جالسًا في حالة حزن على قاعدة أو صخرة، أو يقف برجلين متقاطعتين أو منتابكنين وقد مال أحد مرفقيه على عصا راعي الغنم بينما الآخر مرفوع على رأسه كما لو كان، بحسب تصور فيرماسيرين Vermaseren، يتأمل مصبره السيء" بعد خصائه لنفسه نتيجة الجنون الذي لحق به ومن ثم موته. إلا أن ماتر ماجنا تتوسل إلى زيوس

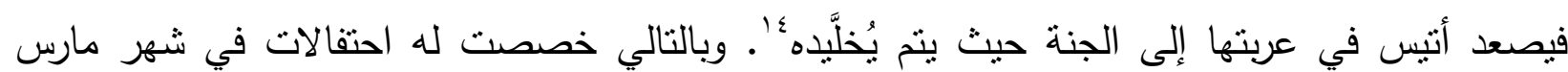
انقسمت إلى جزءين: جزء لذكري وفاته tristia، وجزء للاحتفال بعودته للحياة ' hilaria.

"ربما يعبر التشابه بين الأزياء التقليدية لأتبس والبارثيين عن الاندماج مع الملابس الثرقية الغريبة. 9 البناطيل الممتدة تحت الركبة أو الفخذ (غالبا مصنوعة من الصوف) من أزياء الأناضول، ظهرت في المصادر اليونانية

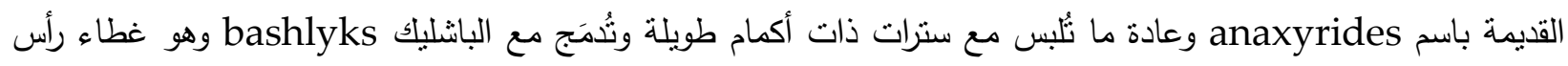

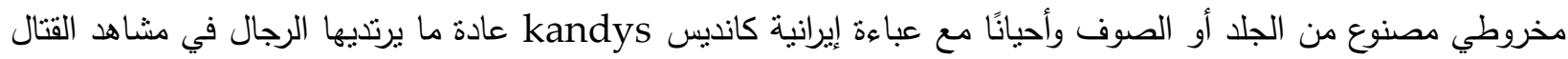
أو المواكب. ويبدو أن مزيج البنطال الضيق والسترات الطويلة والباشليك هو زي عنكري فارسي. في في الواقع، يصف هيرودوت الفرق الفارسية والميدية لجيش زركسيس Xerxes بأنهم يرتدون bashlyks وخيتون chiton بأكمام منقوشة هينة

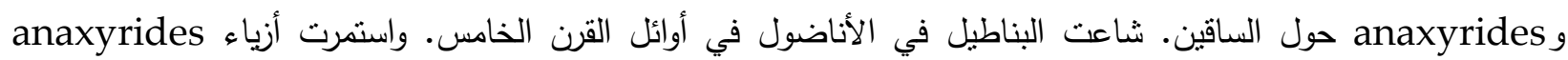
طوال القرن الرابع حتى اختق من الأناضول في القرن الثالث. على عكس الخيتون ذي ذاعي الأكمام والكانديس، لم يتم تبني anaxyrides أكياس. وقد أصبحت anaxyrides في الفن اليوناني تعبيرًا عن "الآخر الثرقي". - TunA S., Dress and Identity in the Arts of Western Anatolia: The Seventh through Fourth Centuries BCE, Brunswick, New Jersey, 2011, 89-92.

‘' آلة نفخ موسيقية، استخدمت من قبل الرعاة اليونانيين وظهرت في جزر كيكلادس في القرن الثالث قبل الميلاد. - JAMES ,M., Twentieth-Century Chamber Music: Routledge Studies in Musical Genres, Routledge, 2003, 48

11 GASPARRO \& SFAmeNI, G., Soteriology and Mystic Aspects in the Cult of Cybele and Attis, Amsterdam: Brill, 1985, 34.2.

12 VERMASEREN, M.: «Legend of Attis in Greek and Roman Art», International Journal of Cambridg University Press, Leiden: E. J. Brill, 1966 , 39-59;

13 Vermaseren, M., Corpus Cultus Cybelae Attidisque (CCCA), V.: Aegyptus, Africa, Hispania, Gallia Et Britannia, Brill, 1986, 255, 435, Corpus Cultus Cybelae Attidisque: Aux Religions Orientales Dans l'Empire Brill, August 1, 1997, 19, 24, 33,77, 78.

14 Vermaseren, Legend of Attis in Greek and Roman Art, PL. XVII.

15 VERMASEREN, Legend of Attis in Greek and Roman Art, 39.

الدلالات الفنية للتعبير عن عملية الخِصِاء من خلال تصوير أتيس وأتباع كيبيلي في العصر الروماني | (ه.r- .بr) 
- ظهرت عدة أنماط وطرز لأتنس، رصدها Vermaseren في عبادة ماتر ماجنا في الدجلدات CORPUS CULTUS CYBELAE ATTIDISQUE (CCCA)I - VII.

\section{${ }^{17}:$ Tristia}

صورة ا: تمثال من الرخام، على رأس أتيس قبعة فيريجيه لها زوائد جانبية ممندة إلى الكتفين وسترة واسعة

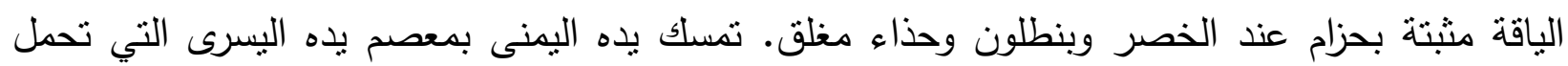
بدورها cyathus أو مغرفة طقسية.

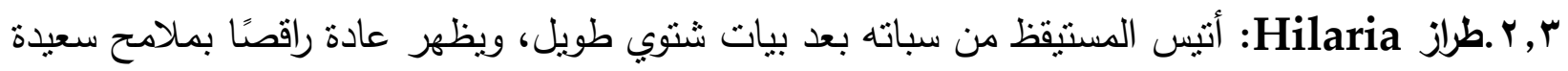

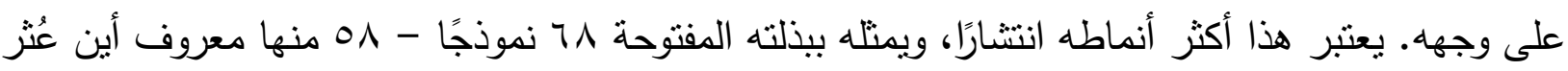
- موزعة كما هو موضتح في شكل الـ وتعود القطع حسب تأريخها إلى الفترة ما بين القرنين الثاني قبل فيل فئل الميلاد والرابع الميلادي. ظهر أتيس بالسترة المفتوحة على حالات متعددة ما بين طفل أو شاب (ليس كرجل ناضج تمائا، لأنه لا يصل إلى هذه المرحلة) حسب حلقات أسطورته المختلفة (الطفولة والثباب والخصاء والموت والبعث) وعبر عناصر منتوعة (منل التراكونا، وتماثيل نذرية من البرونز ، ونقوش نذرية وجنائزية،

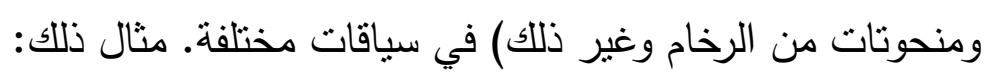

صورة r: تمثال من التراكوتا محفوظ في متحف Pergamon ببرلين، يرجع تاريخه إلى القرن الأول قبل

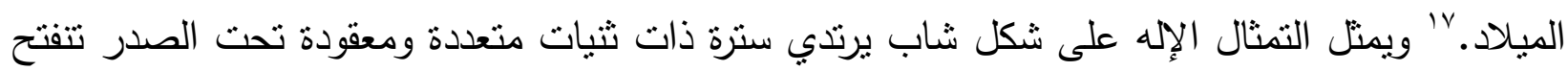

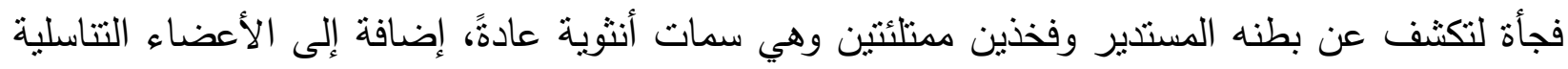

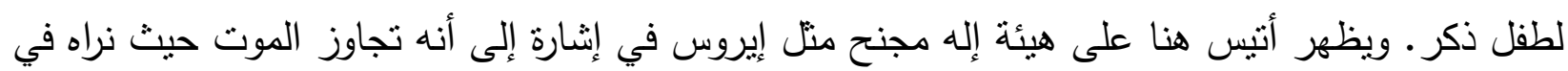

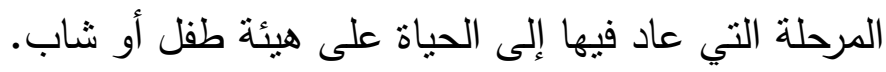
صورة r: طراز لأتيس hilaria من القرن اميلادي`'، النموذج هنا من البرونز لأتيس راقص على أطرف

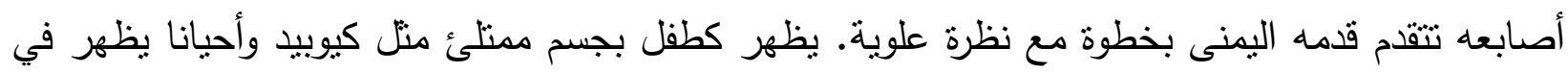

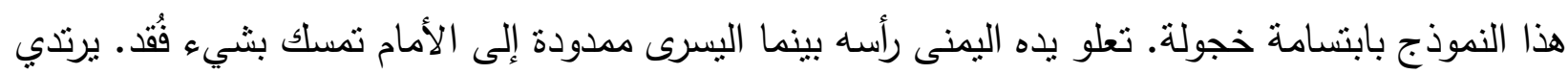
tunica manicata

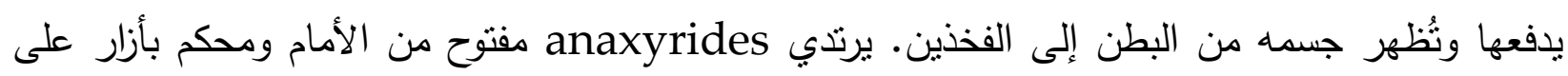

16 Vermaseren, Corpus Cultus Cybelae Attidisque (CCCA) VII: Musea Et Collectiones Privatae, Brill January 1, 1977 , PL. xvi,xvii,xviii,xix.

17 Vermaseren, CCCA ,I, Asia Minor, BRILL, 1977, 495.

${ }^{18}$ GOSE ,E.:«Bronze-StatueUe eines Attis aus der Mosel bei der Trierer RihnerlwUcke», Trierer Zeitschrift $27,1964,40$. 
مسافات منباعدة وحذاء مغلقًا يرتفع إلى الكاحلينو' من نوع يعود إلى نهاية القرن الأول الميلادي أو بداية

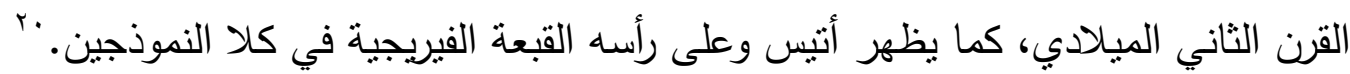
r, r.هناك طراز آخر لأتيس قد يمثل لحظة الموت أو اليقظة كما في:

صورة ؟: تمثال نادر لأتيس من الرخام عثر عليه في أوستيا محفوظ بمتحف لاترانو ويعود إلى القرن الثاني الميلادي" ـ تم تمثيل أتيس هنا منكئا بذراعه الأيسر على رأس جالوس Gallus أو أجدوس (ما يرمز إلى النهر الذي مات بجواره في أسطورته). يبدو وجه أتنس متألما بملامح أنتوية، ثيغطي الخيتون ساقيه المثتيتين وهو يرتدي صندلًا وعباءة ملفوفة على كتفيه. في اليد اليمنى باقة زهور، وتتوج رأسه مجموعة من الزهور ونبتات الصنوبر وإكليل على شكل أشعة الثمس يعلوها هلا وقبعة فريجيه. يغطي الصدر وشاح علوي لكن تظهر العانة تظهر - نتيجة إيذاءه لنفسه - مرسومة مثلما نرى في تماثيل فينوس. وهنا أزال الفنان أي مشهر للأعضاء التتاسلية الذكرية واستبدلها بالعانة الملساء بينما نستكمل انحناءات الجذع الخصائص الأنثوية للتثنثال.

\section{ع .أعضاء طائفة كيبيلي ومهامهم في العبادة:}

وصلت هذه العبادة رسميا إلى روما في نهاية الحرب البونيقية الثانية (ع •. قبل الميلاد)، بعد أن أوصى العرافون المختصون بنبوءات سيبيل ribylline Oracles بضرورة اللجوء إلى الإلهة كيبيلي

Ta 3374,pl II,I:I يوجد نموذج محفوظ في متحف طنطا برقم - SEIF E. M.: «De la Société Royale d'Archéologie d'Alexandrie », Bulletin 46, Bronze Hoards from Sais:Sa el-Haggar 2001, 22.

• غالبًا ما ترتبط القبعة الفيريجيه - وهي قبعة ضيقة ذات رأس مدبب مرن - بالأناضول، وفي الفن الروماني يثار إليها كتتويع على غطاء الرأس الموصوف بالكلمة اليونانية القديمة LIDDEL, G., H., \& SCOTT, R., A Greek-English Lexicon. Clarendon Press,1940,227.

تظهر الأدلة الأثرية على ارتداء أهل الأناضول للقبعة في الفترة الرومانية، لكن تظل الرابطة "الفريجية" لغطاء الرأس في الفترات

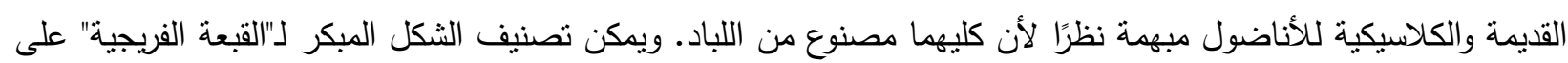

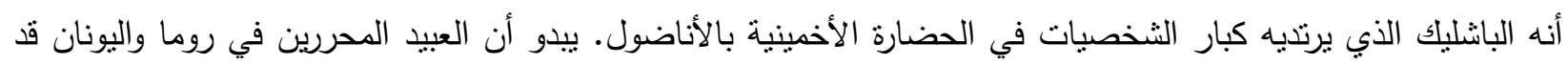
ارتدوا القبعة الفريجية ربما لشيوع فكرة أن فريجيا مصدر للعبيد، ومن ثم فهي الرداء التقليدي للعبد المحرر • ومع ذلك، بمكن أيضًا رؤية القبعة الفريجية على رؤوس الداكيين - Dacians على عمود نراجان الذي يحيي ذكري الحروب مع الداكيين

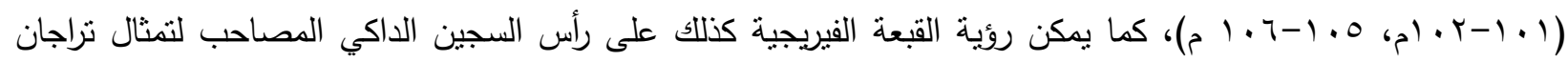
الذي عثر عليه في مدينة Laodicea لادوكية التركية، وعلى رؤوس البارثيين على قوس سبتيموس سيفيروس الذي يعود إلى راسى القرن الثاني الميلادي وهو أيضًا يحيي ذكرى انتصارات الرومان على الإمبراطورية الباريثية، والعديد من التمثيلات الرومانية

$$
\text { الأخرى لغير الرومان (إلى آخره). }
$$

- TUNA. S, Dress and Identity in the Arts of Western Anatolia, 77.

21 Vermaseren, Corpus Cultus Cybelae Attidisque III, 123- 394, CCXL IV.

rr هي النبؤات المرتبطة بتفسير الرؤي والاحلام من خلال العرافين في المعابد=

الدلالات الفنية للتعبير عن عملية الخِصِاء من خلال تصوير أتيس وأتباع كيبيلي في العصر الروماني | (ه.ب- .بrم) 
واتخاذها حليفًا دينيًا رئيسيًا في حرب روما الثانية ضد قرطاجة (1 اYY-1 •r قبل الميلاد)، فتأكد أن هزيمة قرطاج على يد روما كانت منوقفة على اعتناق الرومان عبادة كيبلي الأم العظمى

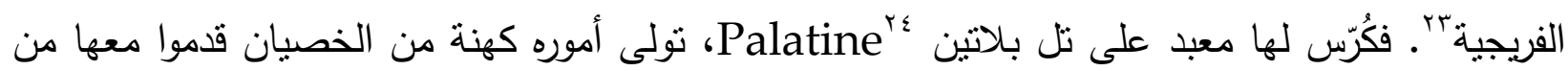
فيريجياهr وقد سجل الشاعر الروماني فيرجيل Vergilius في ملحمته الثهيرة المعروفة بالإنيادة طقوس ومميزات عبادة كيبيلي في طروادة؛ واعتبرها والدة الإله جوبيتز وحامية أمير طروادة إينياس في رحلته من طروادة إلى ايطالياّب. لذا فقد رسخ الرومان فكرة مؤداها أن كيبيلى لم تكن أجنبية، بل كانت في الأصل إلهة أجداد الشعب الروماني عن طريق الأمير الطروادي أينياس بطل حرب طروادة الثهير . فكانت أعياد ماجنا ماتر في عصر الجمهورية منقسمة إلى احتفالين: احتفال فريجي في شهر مارس، واحتفال يوناني في شهر أبريل. ومن عصر الإمبراطور كلوديوس (1 (-یى ميلادي) فصاعدًا، دخلت الأعياد الفريجية لشهر مارس التقويم الروماني الرسمي لتصبح عطلة رسمية، ثم تلا ذلك بعض التغيرات في العصر الأنطونيني (79r9 ( ميلادي) حيث سُمح للسيدات باصطحاب كاهنات ماجنا ماتر لأول مرة كما أضيف طقسا أضحية الثور Taurobolium وأضحية الكبش Criobolium اكتثاف حفرة عميقة كانت تستخدم لهذا الأمر، كان يُسكب على المبتدئين دم ثور كنوع من الأضاحي لكيبيلي وج. وانتشرت عبادة كيبيلي في المدن الإيطالية والمقاطعات الغربية للإمبراطوربة كعبادة رومانية. كان Archigallus بمنل رئيس الكهنة أو رئيس الطائفة، يتبعه sacerdos. وكان الكهنة رجالًا ونساء، يليهم الأتباع المخلصون Galli. ومن مهام الـ Archigallus الأساسية التنبؤ بأوامر الآلهة والإثراف على التضحيات الثوروبوليكية (طقوس Taurobolium) طلبًا لخلاص الإمبراطور سواء في روما أو في مدن إيطاليا أو أغلب مقاطعات الإمبراطورية. •ج وهو دائمًا مواطن روماني يتم اختياره من خلال

=CARTLEDGe, P., Cambridge Illustrated History: Ancient Greece. New York: Cambridge University Press, 1998.

23 BEARD, M.:" The Roman and the Foreign", The Cult of the 'Great Mother' In Imperial, 1994, Rome: Ann Arbor, University of Michigan, 1994, 164-90, 168,.

24 ROLler, L., E.: «Attis on Greek Votive Monuments», The Journal of the American School of Classical,vol 63,1949, 273.

${ }^{25}$ BEARD, M., The Roman and the Foreign, 168, 178-9.

26-virgil, translated by H. RUSHTON FAIRCLOUGH, Loeb Classical Library. Harvard University Press: Cambridge, 1916, IX 77.

${ }^{27}$ CUMONT, Le Taurobole et le Culte de Bellone, Revue d'Histoire et de Littérature Religieuses, 1901, 6.2.

28 GRANT, S.:"Criobolium», Translated by CHISHOLM, Hugh (ed.), Encyclopædia Britannica, 11 ${ }^{\text {th }}$ d. Cambridge University Press, 1911.505.

${ }^{29}$ VeCIHI. Ö.: «The Shaft Monuments and the 'Taurobolium' among the Phrygians», Anatolian Studies, Vol. 47, 1997, 89-103.

${ }^{30}$ ROBERT T., The Cults of the Roman Empire, The Great Mother and her Eunuchs, Wiley-Blackwell, 1996, 51. 
الأسرار المقسة Quindecimviri Sacris Faciundis، وتشتمر خدمته مدى الحياة'ّ. أما الكاهن والكاهنة من أصحاب الأصل الفيريجي فسؤولون عن المواكب، ليس فقط موكب lauatio ولكن أيضًا مواكب شهر مارس arbor intra canna intrat. وبهذه الصفة يحملون صور الآلهة على صدورهم ويطوفون في المدينة توسلا للأعمال الخيرية، مع أدائه بعض التضحيات مثل خصاء أنفسه خلال احتفال

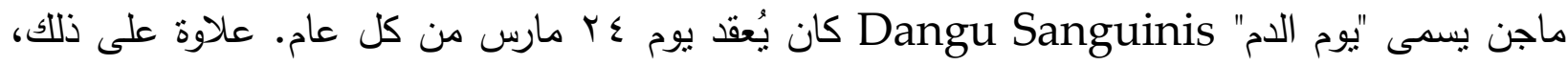

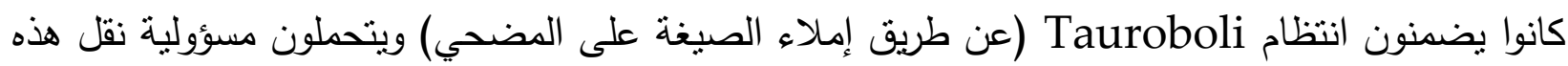

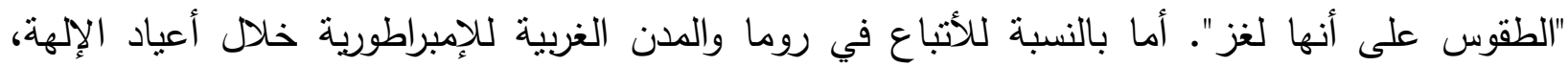

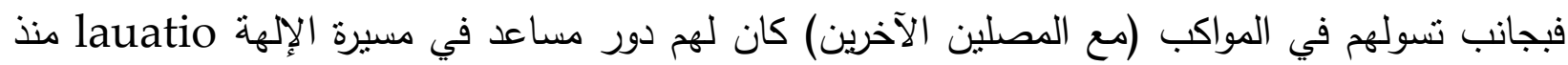

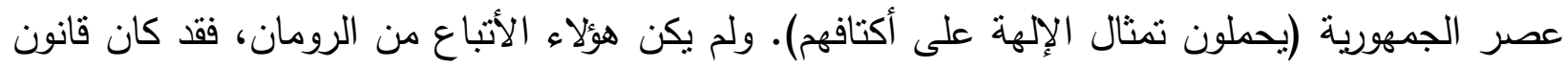

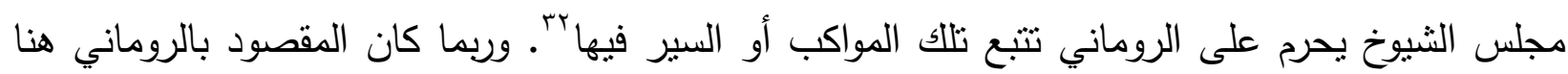

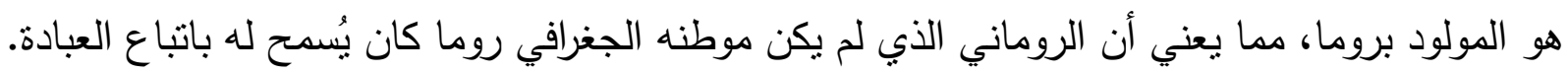

\section{ه .نماذج تصوير الكهنة والأتباع:}

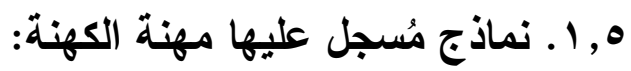

(صورة 0) بrاب: شاهد قبر جنائزي عثر عليه في Portus بالقرب من أوستيا، يعود إلى النصف الثاني من القرن الأول قبل الميلاد. نقش عليه اسم L. Valerius Fyrmus كاهن إيزيس في أوستيا، وأم الآلهة

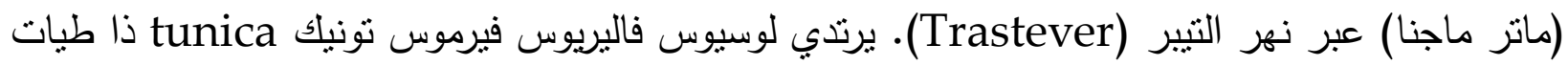

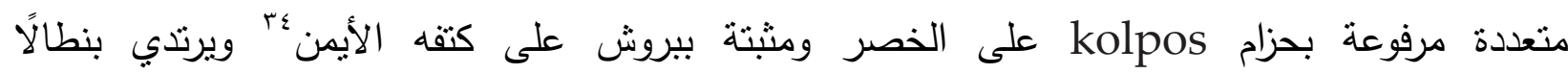
anaxyrides

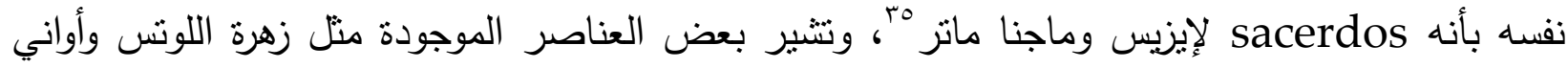
الطقوس إلى إيزيس، بينما يشير السوط flagellum في يده اليمنى إلى عبادة ماجنا ماتر.

31 LesLey A., Roy A., Adkins Dictionary of Roman Religion, Oxford University Press, 1996. 91.

rrionysius of Halicarnassus داخل النظر نصوص الأدبية بالبحث

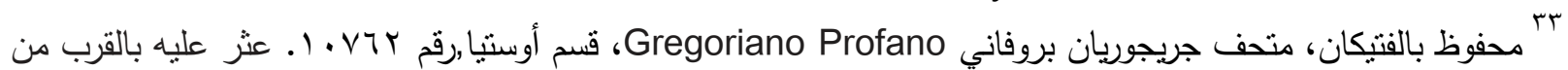

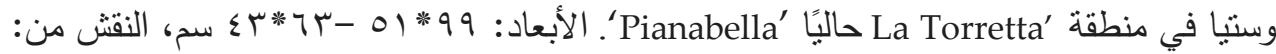

VALERIUS, L., fil(ius) Fyrmus / sacerdos Isidis Ostens(is) / et M(atris) d(eum) tra (n)stib(erinae) fec(it) sibi ,

- CIL XIV, 429.

Vermaseren, Corpus Cultus Cybelae Attidisque, I., 133-134 No. 422 , 1, 266.

34 Sinn, Friederike.. Vatikanische Museen, Museo Gregoriano Profano ex Lateranense, Katalog der Skulpturen. Vol. 1, Die Grabdenkmaler 1: Reliefs, Altäre, Urnen. Monumenta Artis Romanae 17. Mainz: von Zabern, 1991, 72-73 No. 39, FIGS. 116-117.

35 Vermaseren, Corpus Cultus Cybelae Attidisque, I. 99.

الدلالات الفنية للتعبير عن عملية الخِصِاء من خلال تصوير أتيس وأتباع كيبيلي في العصر الروماني | (ه.ب- .بr) 


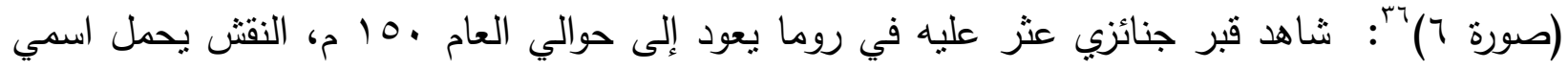
archigallus وهو مهذى من Massus وظيفته الدينية M. Aquilius Primigenius tusculanorum يتوسط باسوس Bassus الصورة وعلى جانبيه شعلتان، تم تصوير قناع الأسد الحيوان المرافق لماجنا ماتز - فوق كتفه الأيسر، وهو يرفع يده اليمنى في إيماءة عبادة بينما يخفض اليسرى ممسكًا بوعاء معدني patera. لا يمكن التعرف على ثيابه تمامًا حيث أنه منحوت كجذع مجرّد، يرتدي mental فوق التونيك تتدلى بشكل فضفاض إلى الأمام على الكتفين. على عكس Fyrmus، لا يرتدي باسوس قبعة بل وشاحًا يغطي الجزء الخلفي من رأسه ويتدلى خلف كتقيه، مثثنًا برباط رأس مع زخرفة في المقدمة في تصوير غير تقليدي لرجل، كما أن شعره مغطى بالكامل^^ ووجهه حليق بلا لحية. ه, ^. نماذج لأتباع ماجنا ماتر عُرفت من مخصصات عبادتها: (صورة \): - تمثال كبير الحجم عُثر عليه بلا رأس في روما في القرن السابع عشر وتم ترميمه آنذاك باسم أنيس. يعود تاريخه إلى أواخر العصر الأنطونيني. جّ" ويؤكد السوط الموجود على ذراعه اليسرى انتماءه إلى عبادة ماجنا ماتر. •؛ يرتدي العباءة الفضفاضة الملفوفة على الكتفين كالمنحوتات التالية، ثنيات وطيات

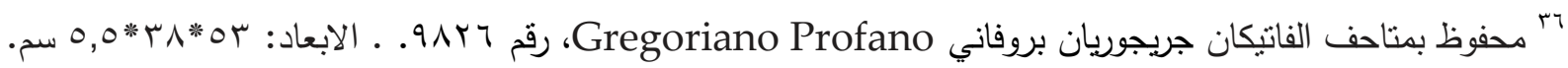

- Sinn, Friederike., Vatikanische Museen, Museo Gregoriano Profano ex Lateranense, Katalog der Skulpturen.

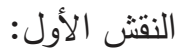

C. Iulio Basso / M. Aquilius / Primigenius / [...] bernali suo b.m.f. / [...] vix. ann. XXXI /[...]usculanor(um). - (CIL VI 19875)-

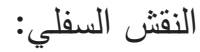

C. Iulio Basso / M. Aquilius / Primigenius / contubernali suo b(ene) m(erenti) f(ecit) / cum quo vix(it) an. XXXI / archigallo Tusculanor (um) / et sibi. - (CIL VI 32466):

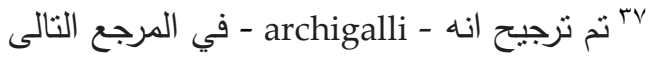

HAEPEREN, Les Acteurs du Culte de Magna Mater, 473-474:

^^مقارنة بتصوير الكاهنات متل " كاهنات فيستا " الذي تم تصوبرهن بأغطية رأس، ورغم ذلك نجد مقدمة شعورهن ظاهرة من

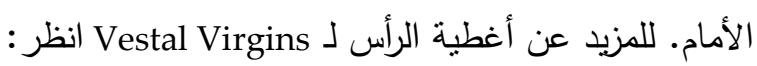

- SIEBERT, A.V.: «Quellenanalytische Bemerkungen zu Haartracht und Kopfschmuck Römischer Priesterinnen», Boreas 18, 1995, 77-92.

- MeKacher, N., Die Vestalischen Jungfrauen in der Römischen Kaiserzeit, Wiesbaden: Ludwig Reichert Verlag, 2006, 44-49.

9" محفوظ في روما بمتحف الكابتولين رقم . الابعاد: 19C 3047/S 19 سم، الرأس لا نتتمي لباقي الجسد، يوجد نقش حديث

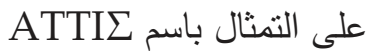

; HeLBIG. W., Führer Durch die Öffentlichen Sammlungen Klassischer Altertümer, 31-32 cat., 1183 Vermaseren, Corpus Cultus Cybelae Attidisque, 64-65, 249.

${ }^{40}$ HelbiG, W.: «Fuihrer durch die Öffentlichen Sammlungen klassischer Altertümer» Rom 2, Wasmuth. 1966, 31-32 cat. №. 1183 : 
الثوب مميزة من جهة اليسار وعلى الفخذين. لم يظهر في الترميم ما إذا كان الرجل قد ارتدى وشاحًا على رأسه إلا أن هناك بقايا وشاح عند الرقبة. حول الرقبة نجد أيضًا مجموعة من العقود تصل حتى الترقوة، تحته سبيكتان دائريتان ولوحة كبيرة على شكل واجهة معبد عليها صورتا ماجنا ماتر وأنيس.

(صورة ^)" ": شاهد قبر لجذع رجل غير ملتح من عصر هادريان. ب؛ يرتدي قلادة تتتهي برأسي أسد أسفلها زخرفة على الصدر لأتيس منت منحوتة رقم ^ إلا انها أصغر • وتتبه ملابسه ما نراه في المنحوتات رقم V• (ا، لكن الأذنين يتميزان بوجود قرطان كبيران فيهما، كما يمتد من الرأس إلى الصدر شربطان طويلان infulae يشبه في ذلك تمثالًا عُثر عليه في موريتانيا القيصرية (صورةץ ( ) بـ وهو النموذج الوحيد القادم من خارج روما. أعلى الرأس وشاح وفوقه تاج مزخرف. للناج ثناث حلقات دائربة، اثتنان منها - الموجودتان على الطرفين - فيهما صورة لأثيس، أما الموجودة في المنتصف ففيها تمثال نصفي لجوبيتز • يظهر الشعر من الأمام تحت الوشاح في موجات مفروقة من الوسط مثل تسربحات الثعر النسائية؛ . بحمل في يده اليمنى زهرة خشخاش تنبثق منها ثلاثة أغصان من الغار يعلوها زوجان من الصنج، وفي اليد اليسرى وعاء فاكهة وأكواز الصنوبر • يعلو الوعاء سوط مزخرف على طرفيه بنقش لرأس جوبيتر وبجواره ثناثة أشرطة جلدية معقودة. على يمين الصورة نحت للعديد من مخصصات ماجنا ماتر (من أعلى إلى أسفل): الطبلة، آلتا فلوت متقاطعان، أحدها منحن والآخر مستقيم، وcista (سلة تستخدم في الطقوس السرية)؛؛ بغطاء هرمي معلقة إلى الحائط بواسطة إسفين.

(صورة9) "؛ : غطاء تابوت رخامي من أوستيا يعود إلى بداية القرن الثالث الميلادي. الغطاء من مقبرة إيزولا ساكراء لرجل مستلق على الغطاء الممثل على شكل أريكة لها وسائد بتكئ برأسه على بده اليسرى وساقه

1 إ" تمثال من الرخام محفوظ في روما بمتحف كابتولين.

-- HeLbiG, W. , Fuhrer durch die Öffentlichen Sammlungen klassischer Altertümer, 25-26 №.1176, Vermaseren , Corpus Cultus Cybelae Attidisque,, 152-153 No. 466, PL. 296-197.

42 Vermaseren, Corpus Cultus Cybelae Attidisque, 153 No. 466. priest'; Helbig, Fuhrer durch die Öffentlichen Sammlungen klassischer Altertüme: 29 - 30 No. 1176. 'Archigallus' Fittschen, K., \& PAUL Z., Katalog der Römischen Portrats in den Capitolinischen Museen und den Anderen kommunalen Sammlungen der Stadt Rom. Vol. 4: Kinderbildnisse. Nachträge zu den Bänden I-III. Neuzeitliche oder Neuzeitlich Verfailschte Bildnisse. Bildnisse an Reliefdenkmailern. Berlin: de Gruyter, 2014, 108.

$$
\text { r" محفوظ بمتحف شرشال برقم V.1. }
$$

Vermaseren, Corpus Cultus Cybelae Attidisque, 53, 146, 39.

${ }^{44}$ BARTMAN. E.: « Hair and the Artifice of Roman Female Adornment», A JA 105, №. 1, Jan., 2001, 1-25.

${ }^{45}$ http://www.perseus.tufts.edu/hopper/text?doc=Perseus:text:1999.04.0063:entry=cista-cn ， Accessed $\underline{28 / 3 / 2021}$

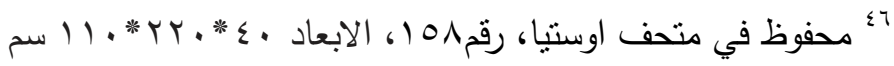

VERMASEREN, C. \& A., The Myth and the Cult., 140-141 , 446 , 1. 282-283;

isola sacra ¿v

- GuIDO. C, Ostia: Isola Sacra: la Necropoli del Portus Romae,1931, 5 . 
اليسرى مثثية أسفلها، ويرتدي حذاء وanaxyrides وسترة بأكمام طويلة. وكما في وضع باسوس، لديه

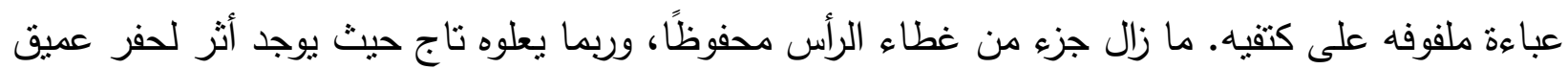

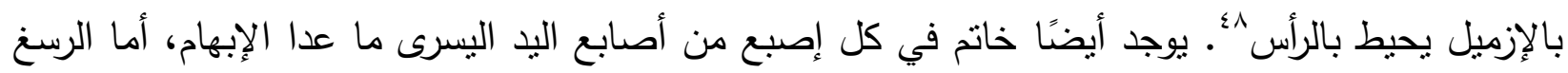

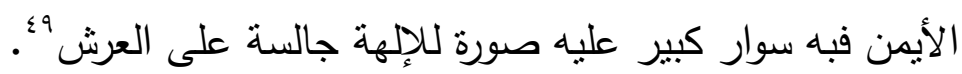

(صورة • 1): تمثال نصفي من القرن الثالث الميلادي عثر عليه في روما.ْ، ربما كان الجزء العلوي من

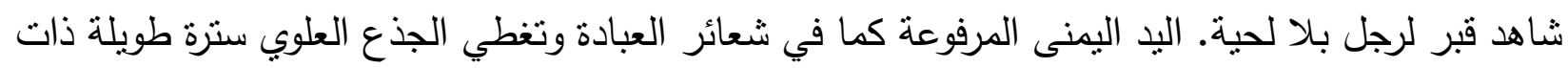

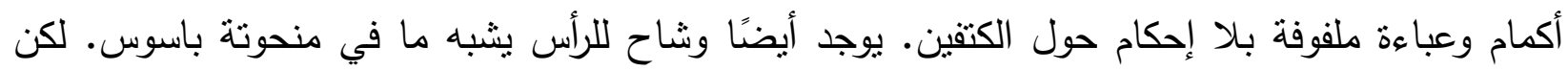

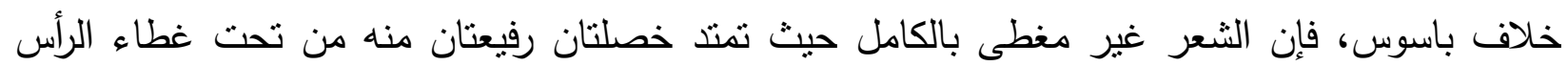

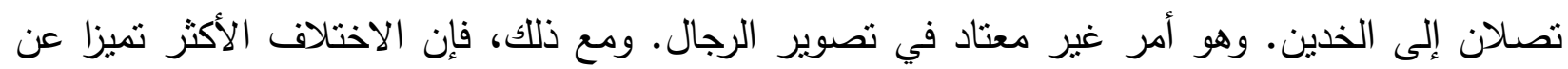

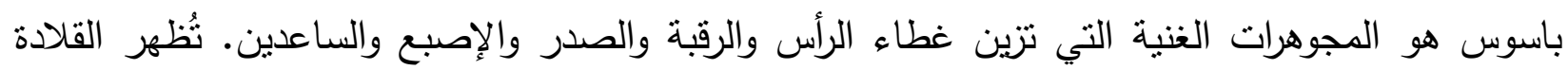

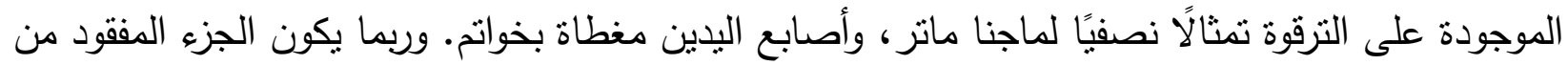

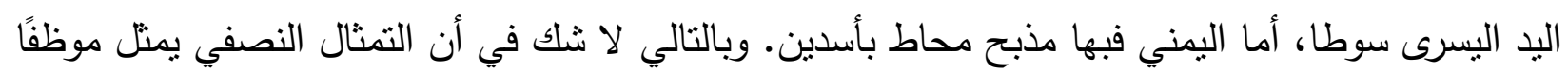
من موظفي هذه العبادة، حتى لو لم نتمكن من تحديد منصبه الديني بدقة. 7 .التحليل الفني لارتباط تلك النماذج (r-V I ) بعبادة كيبيلي:

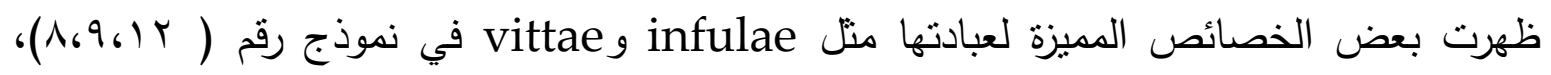

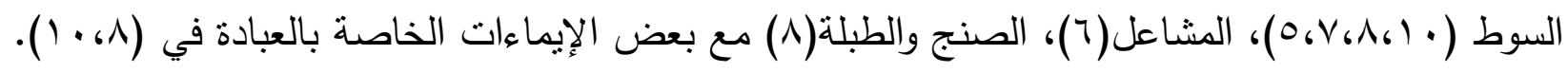

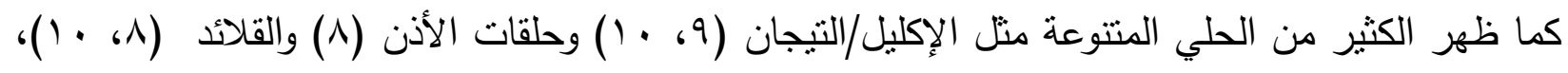

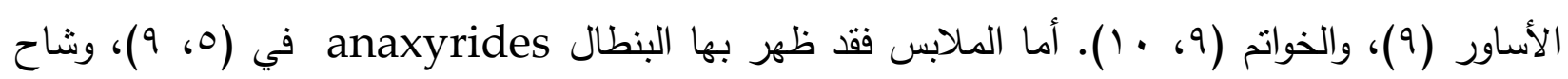

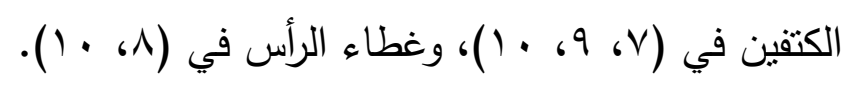

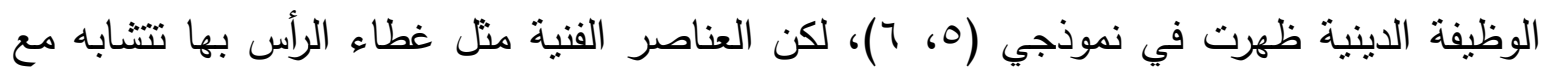

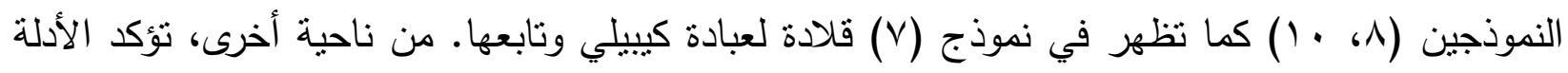

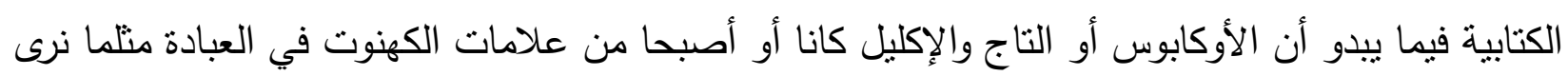

48 Vermaseren, C. \& A., The Myth and the Cult, 141.

${ }^{49}$ FrAnÇOISE,V.H., Rappresentazioni dei Ministri della Mater Magna a Roma e nelle Province Occidentali dell'Impero, 2011, 472 ; RIEGER, ANNA-KATHARINA: “Lokale Tradition versus Überregionale Einheit: Der Kult der Magna Mater." Mediterranea 4,2007, 94-97.

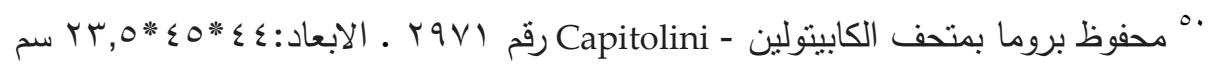

BALTY, J.: «Lexicon Iconographicum Mythologiae Classicae: LIMC. 8,2 Thespiades - Zodiacus et Supplementum Abila - Thersites»; Zürich; München: Artemis-Verl., 1997, 744- 766,763 №. 123. LIMC 8: $744-766.763$ №. 123.

${ }^{51}$ Vermaseren, Corpus Cultus Cybelae Attidisque, 65 - 66, 250. 
نموذج (9)؛ هذا على الرغم من أن الصورة المؤكدة الوحيدة للكاهن (L. Valerius Fyrmus) لا تُظهر أبا

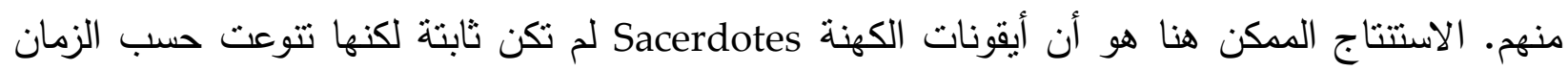

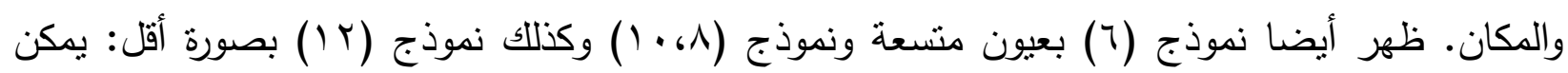

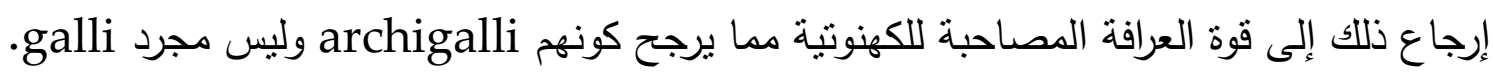
V. المدلول الفني للتعبير عن عملية الخصاء من خلال تصوير أتيس وأتباع كيبيلي في العصر الروماني

\section{1, ا ـ مفهوم الخصاء عند المواطن الروماني من خلال الأدلة الأدبية:}

حظيت ماجنا ماتر منذ قدومها إلى روما في أواخر القرن الثالث قبل الميلاد بالتقدير والإقبال على آلى

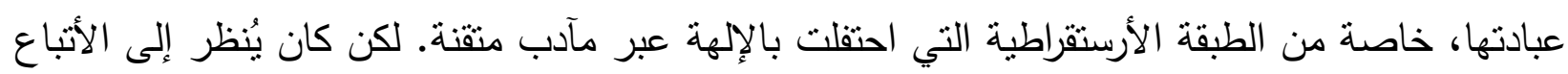

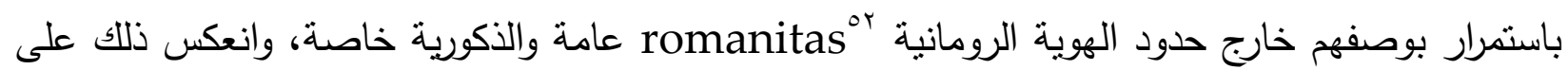
كتّاب تلاك الحقبة (منذ عصر الجمهورية وبدايات الإمبراطورية):

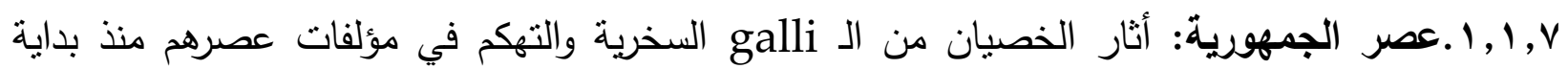

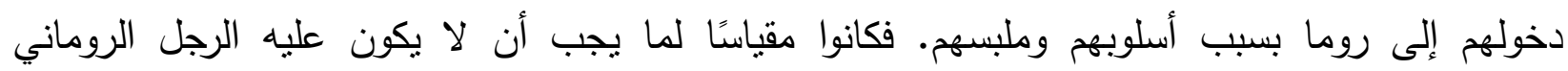

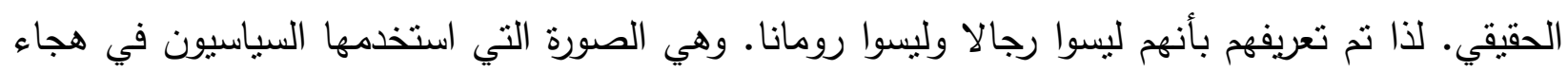

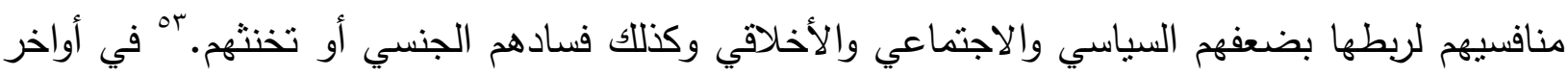

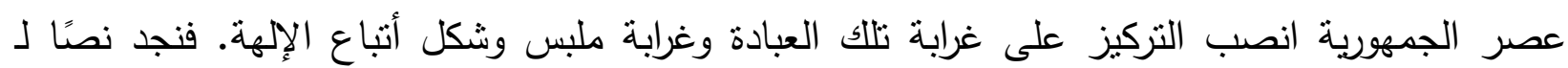
Talli garro

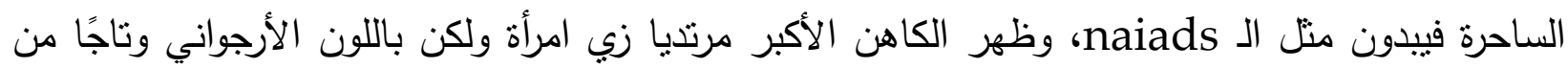

https://en.wikipedia.org/wiki/Tertullian- مصطلح يقصد به الهوية الرومانية أو الطريقة الرومانية، استخدمه(ترتليان

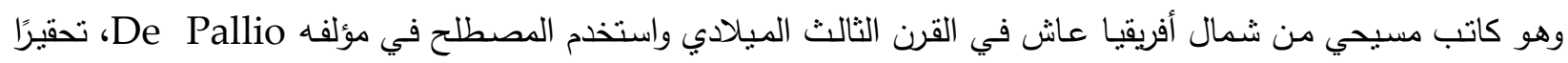
لمعتقي الثقافة الرومانية من موطنه الأصلي قرطاج. كما استُخدم حديثًا في الإثـارة إلى مجموعة من الدفاهيم والممارسات

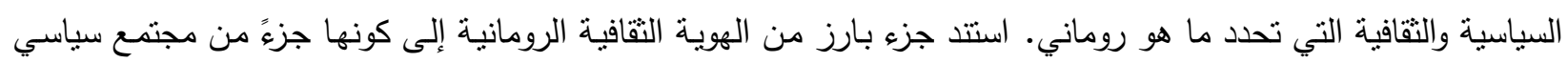

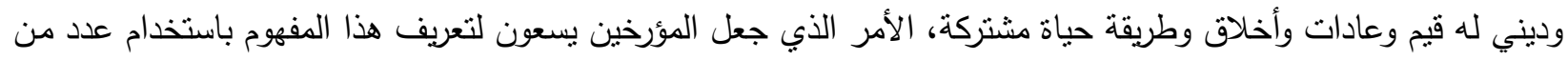

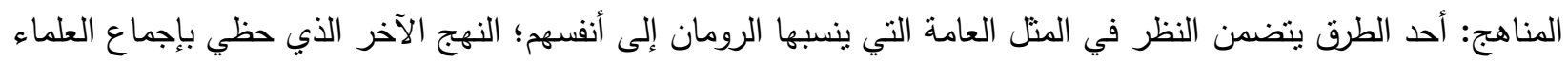

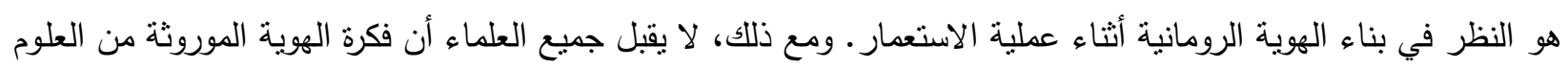
الاجتماعية كافية لفهم ما يجب أن يكون رومانبًا.

Gazd A., Elaine, K. , The Ancient Art of Emulation: Studies in Artistic Originality and Tradition from the Present to Classical Antiquity, 2012, 4.

53 ANTHONY. C.: "Moral Appearance in Action: Effeminacy", In his Controlling Laughter: Political Humor in the Late Roman Republic, Princeton, NJ: Princeton University Press, 1996, 128-73.

الدلالات الفنية للتعبير عن عملية الخِصهاء من خلال تصهوير أتيس وأتباع كيبيلي في العصر الروماني | (ه.r- .بr) 
الذهب المرصتع بالأحجار الكريمة"ه؛. إذن وفقا لفارو، فإن أتباع ماتر ماجنا من الغالي والكاهن الأكبر

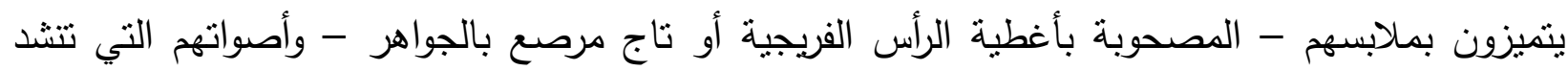

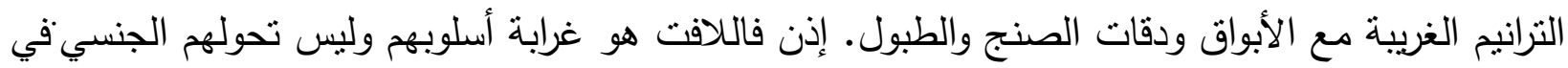
حد ذاته.

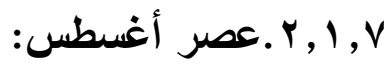

استمر الانبهار ذو الحدين بالممارسات الغريبة للأتباع في ذلك العهد (rV قبل الميلاد-ــ ا ميلادي)

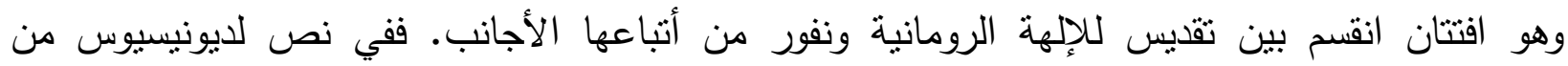
هاليكارناسوس، وهو مؤلف يوناني كتب عن روما في أواخر القرن الأول قبل الميلاد، أكد أنه على الرغم من

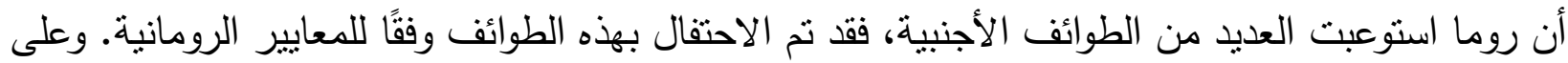

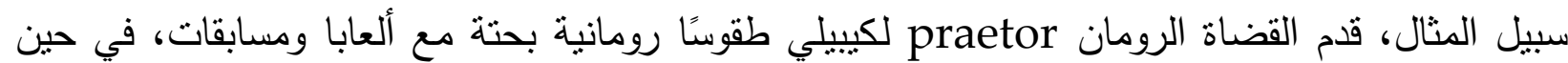
كان الكاهن والكاهنة الفريجية برتدون قلائد للإله على صدورهم ويحملون تماثيله عبر المدينة توسلًا

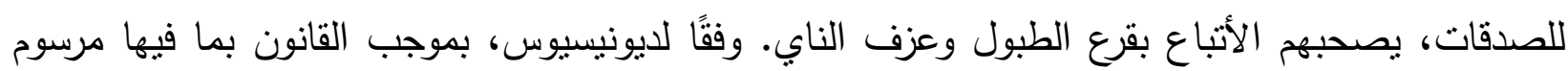
خاص من مجلس الثشيوخ، مُنع أب روماني من المشاركة في الموكب أو ارتداء الأردية المبهرجة أو تبني

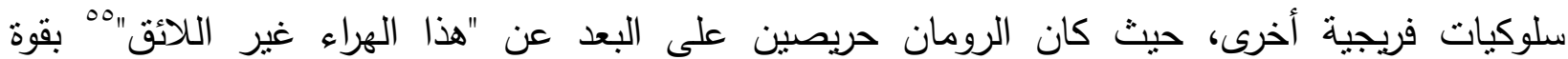
القانون. V , l,V

أدى ظهور الإمبراطورية إلى تغيير جذري في التقافة السياسية لروما التي تتكلت فيها الهوية الرومانية

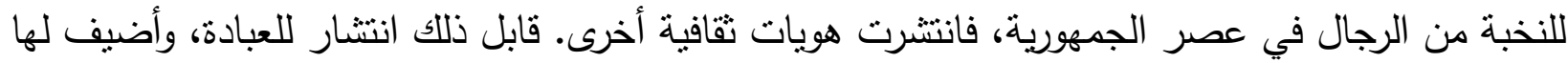

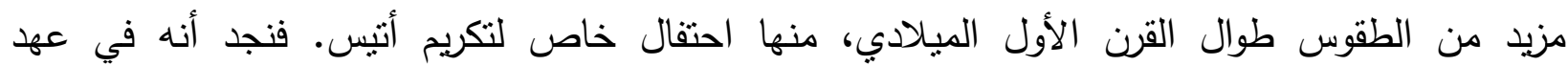
arbor الإمبراطور كلوديوس (إ-ــ ميلادي) قدمت إلى معبد بالاتين سلسلة من الطقوس الجنائزية intrat ترمز إلى أتيس)، لقضاء وقفة تستمر طوال الليل، إضافة إلى الدم (ع r مارس). في القرن التالي، في عصر التصار

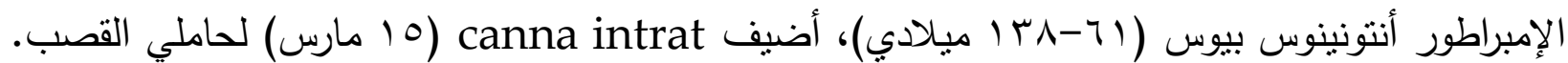

${ }^{54}$ Marcus Terentius Varron, Satires Ménippées. 4. Epitaphiones - Eumenides, édition Jean-Pierre Cèbe, Ecole Française de Rome, 1977 ; Eumenides: "Partim Uenusta Muliebri Ornati Stola" (120B), Coronam ex Auro et Gemmis Fulgentem Gerit” 121B,) “ut Naides Undicolae” (130B).

55 DiONYSIUS OF HALICARNASSUS, Roman Antiquities, translated by ERNEST CARY, Harvard University Press 1937. 2.19.3-5, BORGEAUD, Mother of the Gods, 70 ,57.

56 JACOB, L.: «Fabulous Clap-Trap: Roman Masculinity», The Cult of Magna Mater, and Literary Constructions of the Galli at Rome from the Late Republic to Late Antiquity, The Journal of Religion 92, №.1, January 2012, 102. 
كما أضيف في ذلك العهد أيضًا أو بعده احتفال عام آخر hilaria، وهو كرنفال يتميز بالسلوك العنيف له. وفي أواخر القرن الأول أو بدايات الثاني الميلادي نم إنثاء وظيفة archigallus، رئيس الكهنوت، شغلها canna intrat في البداية مواطنون رومانيون "متحضرون" وجادون من مهامهم، بالإضافة إلى إجراء والتضحية المصاحبة له،ه، الإشراف على طقوس أخرى جديدة ضمنها Taurobolium، وهي التضحية بالثور التي تقام غالبًا من أجل الإمبراطور الحاكم وهانت في ذلك الوقت تقام في حرم معبد بلاتتين. نتيجة هذا التوسع والإضافات، كونت ماتر ماجنا ومعاونوها صورة عامة أكثر وضوحًا، وتضاءل القلق الذي بدأ مع العبادة عند دخولها في بدايات الجمهورية. لكن يبدو أن الوجود العام الدائم والمتزايد أثار رد فعل عنيفًا مماثلًا عند الكتاب. فعلى سبيل المثال، يهجو مارتيال " " محاورا له في أحد نصوصه على هذا النحو: "أكثر خصاءً من الخصي المترهل، وأكثر أنثوبة من Celaenaeo [والمقصود أتيس] الذي يصرخ باسمه الكاهن المذهب

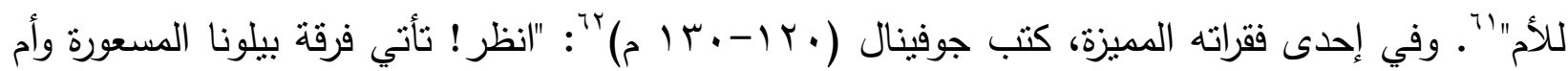
الآلهة جنبًا إلى جنب مع خصي ضخم، وجهه يقده صديقه المنحرف. منذ زمن بعيد التقط شظية وقطع أعضائه التتاسلية الرخوة. الفرقة الصاخبة والطبول الثائعة يسودها الهدوء في حضوره ووجنتاه يعلوهما قبعة فريجية. بصوت عالٍ يقول للمرأة أن تحذر قدوم سبتمبر والرياح الجنوبية، إلا إذا طهرت نفسها بمائة بيضة وأهدته فساتينها القديمة ذات اللون الخمري للتأكد من زوال أي كارثة خطيرة أو غير منوقعة. الملابس للتكفير

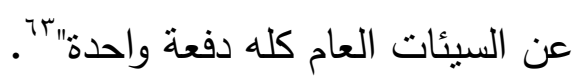

لكن يبدو أن هذا العداء الثديد - والغريب في بعض الأحيان - للأتباع، والذي بلغ ذروته في أوائل القرن الثاني الميلادي، قل لاحقًا. فمع بداية القرن الثالث الميلادي تلاشت اللغة الحادة تجاه الأثباع وحل

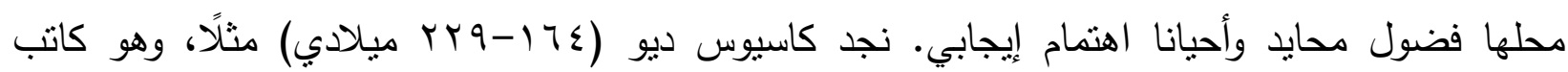

57 CArcopino, J., Aspects Mystiques de la Rome Païenne, Paris, 1942, 49-75.

58 CARCOPINO, Aspects Mystiques de la Rome Païenne, 76-171.

59 PHILIPPE. B.: “Taurobo- lion,” In Ansichten Griechischer Rituale: Geburtstags-Symposium fur Walter Burkert, Castelen bei Basel, 15. bis 18. Marz 1996.

• •

$$
\text { أشهرها كتاب إبيجراما Epigram الذي نشر سنة } 1 \text { م م في روما. }
$$

- FitzGeralD, W., MARTIAL: The World of the Epigram, Chicago: Univ. of Chicago Press, 2007.

61 "Spadone cum sis Eviratior Fluxo, et Concubino Mollior Celaenaeo, quem Sectus ululat Matris Entheae المقصود . Gallus",Martial, Epigramma 5.41, translated by Shackleton-Bailey in LCL, 1:393. "اتيس concubino mollior Celaenaeo.

$$
\text { זٓ هجاءات جوفينال: عرف له } 17 \text { قصيدة مقسمة على خمس كتب }
$$

63 “Ecce furentis Bellonae matrisque deum chorus intrat et ingens semivir, obsceno facies reverenda minori, mollia qui rapta secuit genitalia testa iam pridem, cui rauca cohors, cui tympana cedunt plebeia et Phrygia vestitur bucca tiara. grande sonat metuique iubet Septem- bris et Austri adventum, nisi se centum lustraverit ovis et xerampelinas veteres donaverit ipsi, ut quicquid subiti et magni discriminis instat in tunicas eat et totum semel expiet annum" ( Juvenal, Saturae, translated by RAMSAY. G. G.press 1918 6.511-21, translated by Braund in LCL, 283).

الدلالات الفنية للتعبير عن عملية الخِصِاء من خلال تصوير أتيس وأتباع كيبيلي في العصر الروماني | (ه.ب- .بr) 
يوناني وعضو في مجلس الثنيوخ ومؤلف لتاريخ روما، يصف الأثباع بأنهم أشخاص مميزون مسنلهمون من

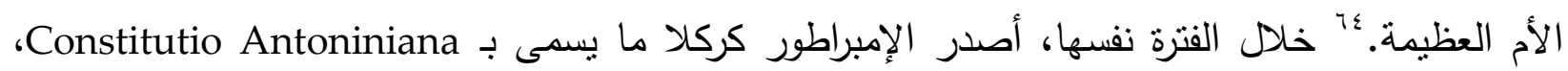

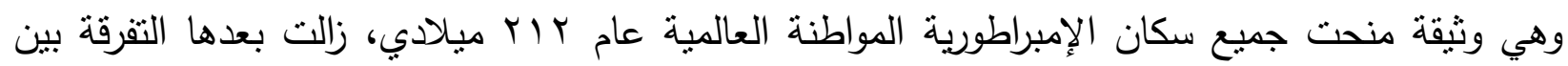

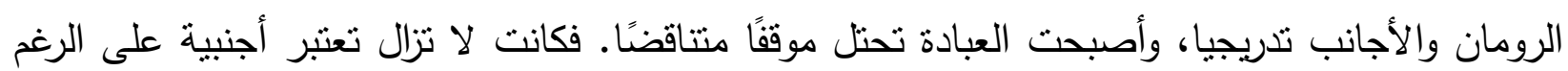
من انضمام عدد كبير من الأرستقراطيين المتمسكين بالهوية الرومانية romanitas إليها، بل وإعلان الإنان

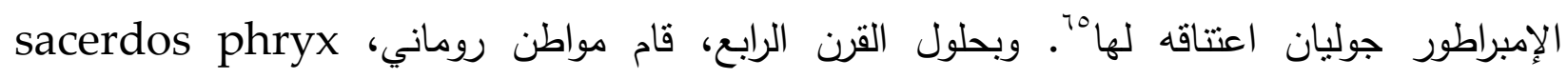
"maximus Flavius Antonius Eustochius إذن اعتبر المواطن الروماني الخصيان نموذجًا للتخنث لكن ذلك لم يمنعه من تقبل عبادة كيبيلي

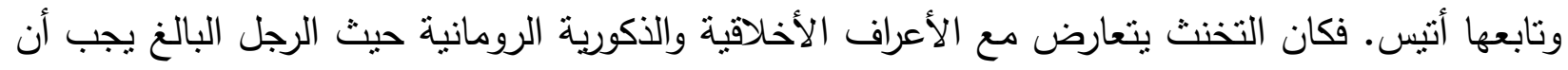
يكون له دور مسيطر بعكس المخنث ذي الوضع الذليل والضعيف الذي يناسب النساء والبغايا والعبيد

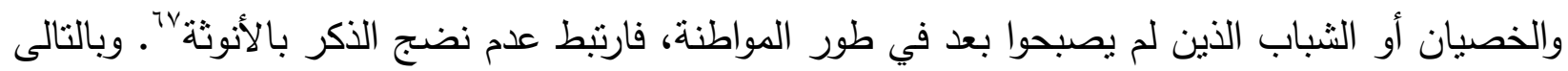

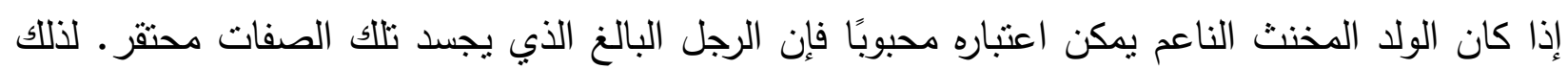

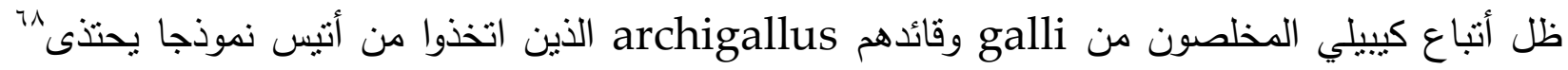

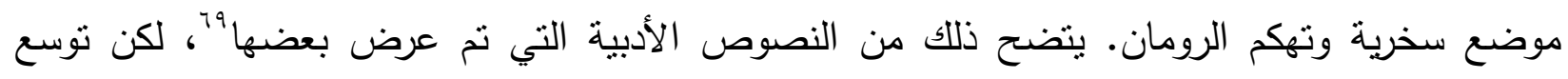

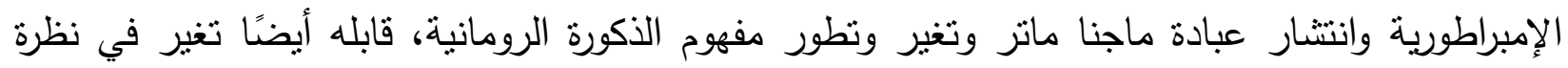
المحتوى الأدبي للأتباع.

V., التصوير الفني لمفهوم الخصاء في ضوء ما سبق من خلال اتخاذ أتيس وأتباع كيبيلي نموذجًا: نقل إلينا الفن الروماني الكثير من الأعمال الفنية التي عكست الاختلافات الجنسية (التشريحية) منها

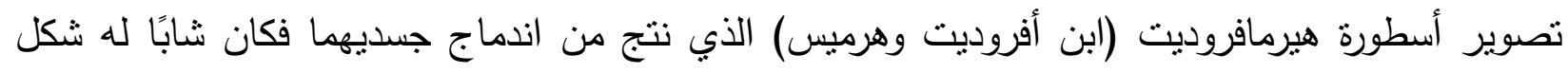

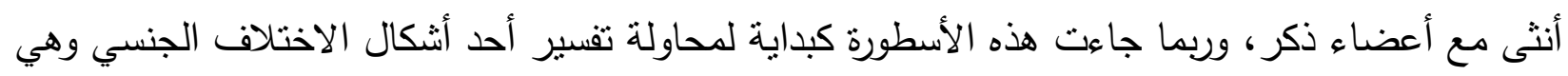

64 Dio CASSIUS, Roman History 48.43.4-6.

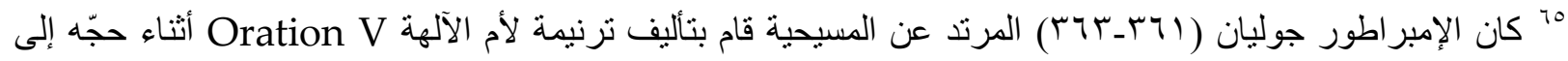
بيسينوس Pessinus، موطن الإلهة الثهير. JACOB L.: «Fabulous Clap-Trap », The Journal of Religion, 92, №. 1, January 2012, 117.

${ }^{66}$ JАСOB :Fabulous Clap-Trap, 117.

67 Judith P. HALlett, Marilyn B. SKINNER, Roman Sexualities, Princeton: Princeton University Press 1997, 54-55.-

${ }^{68}$ BEARD, M.: "The Roman and the Foreign,,164-90.

Ov. Fast. 4.221-44،Ov. Fast. 4.179-90; بلنزيد -https://www.theoi.com/Text/OvidFasti4.html Accessed 28/3/2021 
التخنث الحقيقي. • أما في حالة التصوير الفني للخصاء، والذي عرف به أتنس وأتباع كيبيلي (وهي عبادة أجنبية) سعى الفنان إلى ملاعمنها مع فكر وخيال المواطن الروماني.

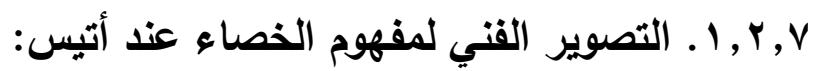

كانت عملية تصوير أتيس المخصي صعبة وغير مقبولة للروماني فأتيس لا يصل إلى مرحلة النضج

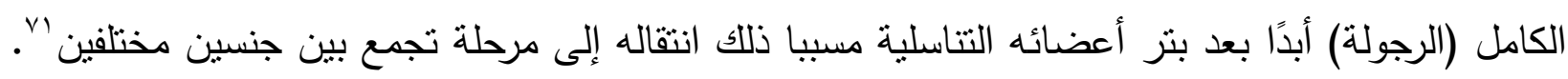
فنموذج رقم ا يظهره شبه عارٍ، مع الاحتفاظ بعباءته والقبعة الفريجية، متسترا على جروحه بيديه كَ'، وهو نموذج يمكن التعرف فيه على أتيس دن خلال زيه المميز وليس تشوهه الجسدي. لكنه نموذج لا يغطي جوانب الأسطورة ولا يوضح ترقية أتيس وتأليهه الذي يظهر مع إضافة الأجنحة في نموذج ب، حيث نرى الجسم بخطوط أنثوية نظهر أيضا في نموذج ء. وهي اللحظة التي تصور غرق أتيس بجانب نهر جالوس أو لحظة استيقاظه (فإكليل الرأس دن أثعة الثمس والهلال وأقماع الصنوبر في يده اليمنى تمثل القوة التي عادت إليه كإله مع التأكيد على هويته الأجنبية عبر القبعة الفربجية) لم أما هنا فالجسد يكثف عن حالة الخصاء. فقد أزيل أي ملمح للأعضاء التتاسلية الذكربة مع المزبد من الخصائص الأنثوية منل منحنيات الجذع التي تظهر أيضا في نموذج r. وهي نماذج لم تتشر وربما لم تلق قبولا عند المواطن الروماني لوحشية التصوير مثل نموذج ع الذي أزيلت فيه الأعضاء، وربما للتخنث الصريح في شكل الإله كما في

• ط التخنث: True Hermaphroditic وهي الولادة بعضوين، ووجود شخص مخنث أو ثنائي الجنس يحوي جسده كلاً من الـ female gonad في آن واحد، أب نسيج مبيضي ونسيج خصوي معاً. للمزيد عن اضطرابات الهوية الجنسية:

- Sharp, V. M.; LeWIS, C. B.; Lieven, N. M. D.: "Bell v Tavistock" . In the High Court of Justice Administrative Court Divisional Court, 202.

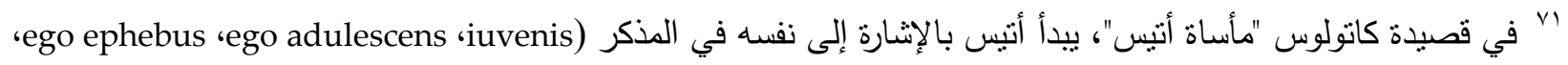

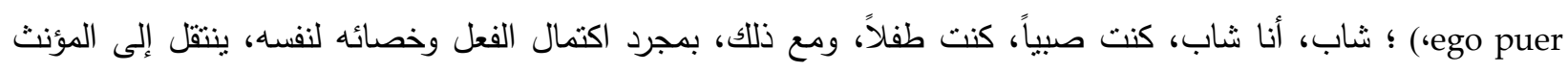
Cego vir ste rilis ero ‘ego mei pars ،ego Maenas ؟ego nunc deum ministra et Cybeles famula ferar) حالته الرجولية يأخذه بعيدًا عن تجربة الذكورة الكاملة من منظور المواطن الروماني ويحوله إلى كائن ذي هوية جنسية غامضة.

- BALMer, J., Catullus: Poems of Love and Hate, Hexham: Bloodaxe, 2004. 63-62-65.68-69.

جايوس فاليريوس كانولوس ربما ولد سنة §^ قبل الميلاد. أو قبل ذلك، وبيدو أنه مات سنة عه قبل الميلاد. كان كانولوس

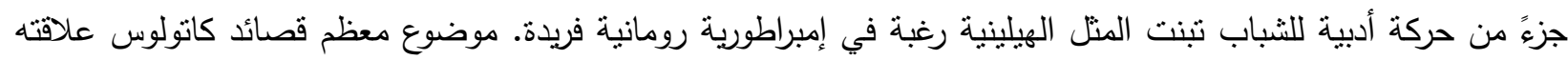

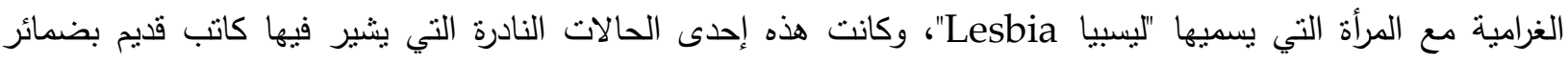
التأنيث إلى كهنة كيبيلى:

HalletT, J.: «Catullus and Horace on Roman Women Poets», Antichthon 40, Thematic issue: Catullus in Contemporary Perspective, 2006, 65-88.

72 VERMASEREN, Legend of Attis in Greek and Roman Art, 35.

rr هي مخصصات و علامات دائما مرتبطة بأتيس: - TURCAN, R., The Cults of the Roman Empire, Oxford, 1996.

الدلالات الفنية للتعبير عن عملية الخِصِاء من خلال تصوير أتيس وأتباع كيبيلي في العصر الروماني | (ه.r- . بr) 
نموذجr. إلى أن نصل إلى نموذج أتيس ذي البطن المكثوف المستدير الذي يظهر أحبانًا بفتحة طفيفة للسترة كتمثيل للأنوثة أو الآلهة المصورة كأطفال (كيوبيد، حربوقراط) وهي رموز أغلبها مرتبط بالأمومة والتربيةء أو بثتيات وطيات متعددة جعلت بعض الباحثين يشبهون تلك الفتحات بفرج الأنثى مo . وهذا يضعنا أمام اقتراحين لتوضيح رمزية تلك السترة: إما أنها رمز لماجنا ماتز وولادته من جديد تحت وصايتها كطل بريء لم يرتكب فعلته المشؤمة؛ أو أنها تعبير عن تخنث الإله بعد تعرضه للخصاء.

\section{التصوير الفني لمفهوم الخصي عند كهنة وأتباع كيبيلي: , Y, V}

اعتاد الخطاب الأدبي في العصر الإمبراطوري السخرية من كهنة وأتباع كيبيلي المخلصين galli،

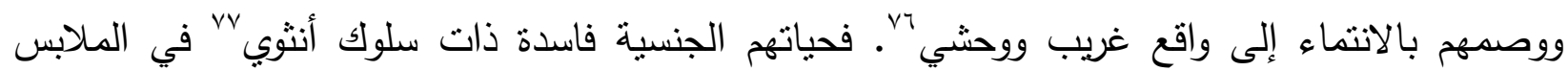
وطرق تصفيف الشعر. ی إلا أن تصويرهم الفني لم يعتد بتلك الأحكام، فلا تُظهر منحوتات الأتباع أي أجساد مخصية منل تلك المذكورة في النصوص الأدبية ولكن تعتمد على الأزياء لتوصبل فكرة الخصاء. وبدلاً من وصفه، يُلَمَّح إلى الخصاء من خلال إثنارات مستمرة إلى مخصصات وصورة أتيس وقد اتخذه الخصيان نموذجا فكان السبب في طقس خصائهم عمومًا. وهناك نموذج تابوت الكاهن المتكئ (صورة 9) والذي تم وصفه على أنه archigalus روماني لارتدائه سوارًا يحمل صورة كيبيلي وأتيس، رغم وجود الأوكابو الخاص بكهنة هذه الطائفة`^. بالإضافة إلى السوار نجده في وضعية استلقاء تتشابه مع نموذج أتيس فينوس ونموذج Capitoline gallus (صورة V). وقد عُرَف بأنه أتنس في مستوي يزيل الفروق بين البشر والآلهة. نموذج ؛ حرص على تصويره بالبنطال والقبعة الفيريجية ربما تشبها بأتنيس أو نأكيدًا للأصل يل الآسيوي. ولا يأتي الاختلاف والتمايز من كون الخصيان ينتبهون بالنساء بل من كيفية تمثيل أنفسهم ليس كإناث أو ذكور ولكن كجنس ثالث يجمع بين الجنسين 'ي. ونلاحظ ذلك من خلال

74 LANCELLOTTI, Attis: Between Myth and History, 80.

75 JAIME, A. E. J. A.: «La Vulva de Atis», Arys 17, 2019.

76 JACOB, Fabulous Clap-Trap, 84-122.

Yv مصطلح السلوك الأنثوي المقصود به هنا Cross dressing وهو سلوك إرِدِاء الملابس المُغايرة لذات الجنس أو إبداء

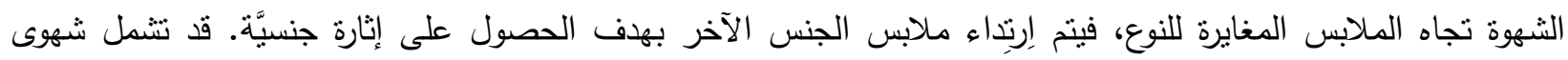

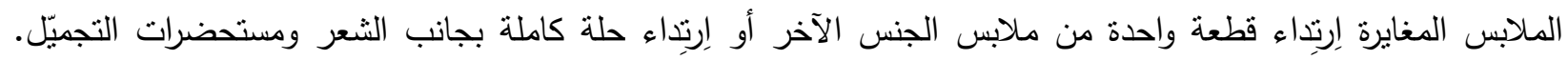

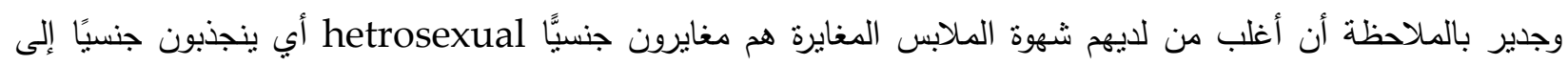
الجنس الآخر • للمزيد:

MiCHAEL, B.F.: « MB. DSM-5 and Paraphilic Disorders. » Journal of the American Academy of Psychiatry and the Law, 2014.

78 JACOB, Fabulous Clap-Trap, 84-122,97.

79 - CAlZA, G.: «Una Figura-Ritratto di Archigallo Scoperta nella Necropoli del Portus Romae.» Historia. Studi Storici per l'Antichita, classica 6,1932, 233.

80 ROLLER, L.E., In Search of God the Mother: The Cult of Anatolian Cybele, Berkeley, 1999, 295.

${ }^{81}$ ROLLE, Attis on Greek Votive Monuments, ROLLER, L.: «The Ideology of the Eunuch Priest», Gender and History 9.3, 
من السمات الجسدية التي تجمع بين نماذج الرجال جميعًا ظهورهم بذقن حليقة فالوجنتان ناعمتان خاليتان من الثعر • وهي سمة غريبة على تصوير الرجال كما هو متعارف عليه عمومًا منذ عصر هادريان، وكونه عكس المتعارف عليه له دلالات مختلفة ז^هما تكون في حالة نماذج أتباع كيبيلي تعبيرًا عن تحولاتهم الهرمونية نتيجة الخصاء أو تأكيدًا على هويتهم الحقيقية. لكن لا توجد عناصر أخرى للوجه تميل إلى

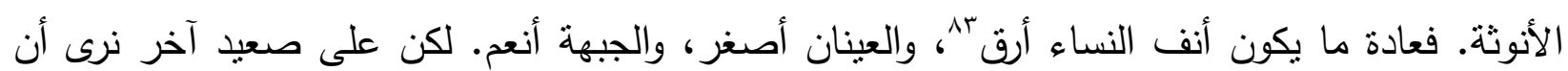
الأذنين بارزتان بشدة بصورة غير أنثوية. : r, r, r, V

لا تختلف ملابسهم عن ملابس الرجال نظرًا للطربقة التي تُلف بها العباءة في عدة طبقات بإحكام حول الخصر • قد يشير تزهل ثثيات العباءة إلى امتلاء معين في الجذع العلوي، ولكن لا يوجد ما يثير إلى وجود ثديين كما هو الحال عند تصوير الإناث. كانت الأقراط على وجه الخصوص في بعض النماذج الموضحة هنا هي التي دفعت إلى الاعتقاد بأنه يتم تمثنل الأتباع "كامرأة"ءء. ولكن من ناحية أخرى، لم يكن ارتداء المجوهرات مقصورًا على النساء في الآثار الجنائزية في العصر الإمبراطوري، كما أنها ليست شائعة في عمليات الدفن. مدويمكن اعتبار ارتداء تلك المجوهرات رمزا لتأثز هؤلاء الأتباع بالثرق. نتيجة ظهور نماذج الأتباع والكهنة بملابس واسعة ومجوهرات فيما عُرف بمصطلح الـ cross dressing استخدم ذلك كدليل سلبي على الخصاء في المراجع القديمة، لكن كان لبعض المراجع الحديثة

rیی في تصوير الخصيان في الأعمال الآشورية غياب اللحية نتيجة التأثنرات الهرمونية للخصاء هو الذي يفرقهم عن نخبة

$$
\text { الذكور الآثورين التي تظهر بلحية }
$$

- SAWYER D., Women and Religion in the First Christian Centuries, London \& New York, 1996, 123, ROLLER, L.: « The Ideology of the Eunuch Priest », Gender and History 9.3, 549.

$$
\text { كهنة إيزياك والوجه الحليق. }
$$

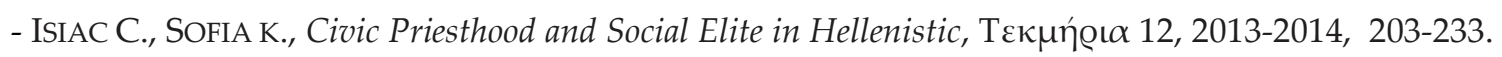

r يشير المرجع الثالى إلى تمثال امرأة بأنف غليظ ويذكر أنها حالة نادرة واسنثنائية.

FitTSCHen, K., E Paul Z., eds. Katalog der Römischen Portrats in den Capitolinischen Museen, 1983 76-77 No. 100, 1. 125-127.

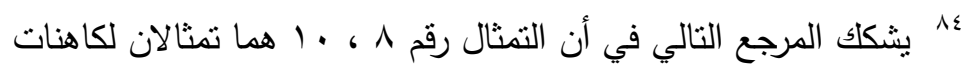

- Haeperen, Rappresentazioni dei Ministri della Mater Magna a Roma e nelle Province Occidentali dell'Impero, 252.

ه^ عثر في كاتاراكتونيوم (كاتريك، برينانيا) في القرن الرابع الميلادي على هيكل عظمي لرجل يرتدي قلادة وسوارا من الأحجار

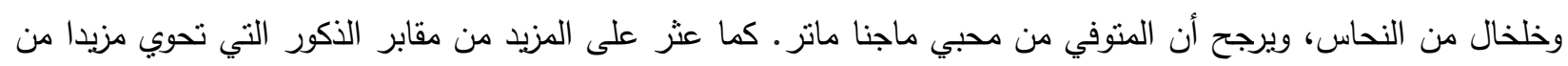
المجوهرات.

WILSON, P.: « Cataractonium: Roman Catterick and its Hinterland ». Inernational Journal of Research Rebort Series , 1958-1997, Parts I-II. York: Council for British Archaeology, 2002, 2:41- 42.

86 BORG, B., Mumienportrats: Chronologie und kultureller Kontext. Mainz: von Zabern, 1996, 167.

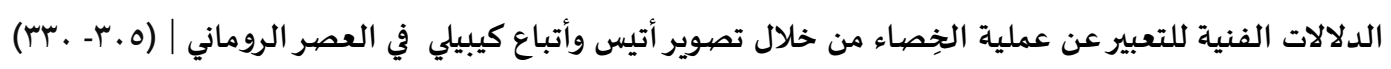


رأي آخر للهروب من هذا التحليل الهننث، فحاول Guido Calza إعادة تصنيف صور الجالي كصور للكاهنات اللاتي خدمن أيضًا في عبادة Cybele مدللا على ذلك بنموذج وحيد ثن التعرف عليه للكاهنة

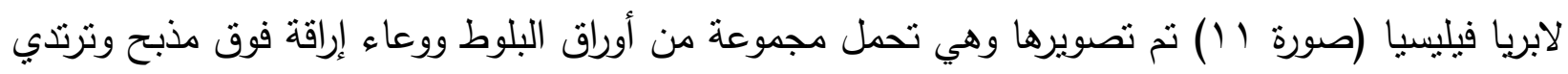

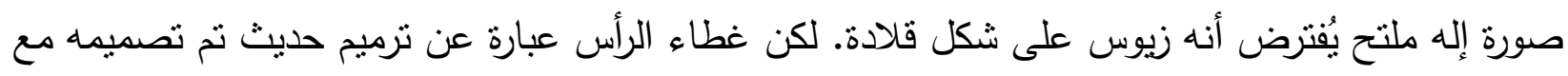

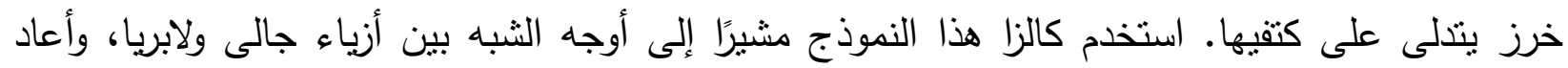
تصنيفه كنساء وهكذا تجنب احتمال وجود غموض متعدد بين الجنسين في تصوير الكهنة المخصيين.

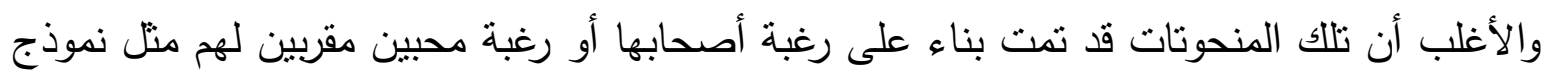
باسوس الذي نم تكليفه من جانب شخص عاش معه يدعى M. Aquilius Primige Nius. فرغم أن رغان

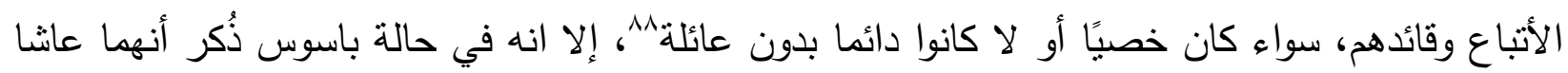

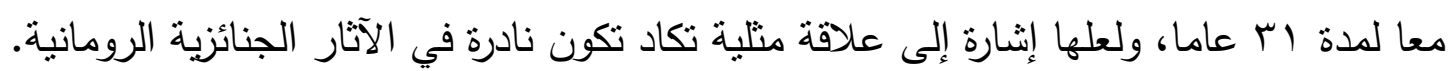
الخاتمة والنتائج: من خلال عرض النماذج الفنية لأتيس وطائفة كهنة كيبيلي وأتباعها وتحليلها أدبيا وفنيا نجد أن:

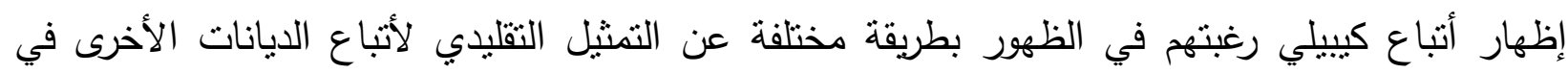
محاكاة لأتثس الذي يصور بزي مميز يدل على الخصاء بدلا من التعرض لتصوير حالة الخصاء نفسها.

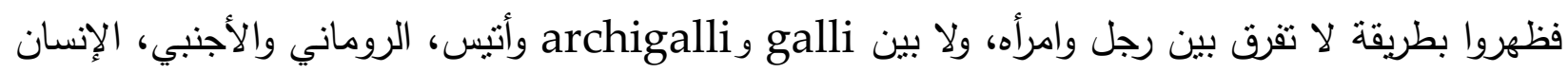

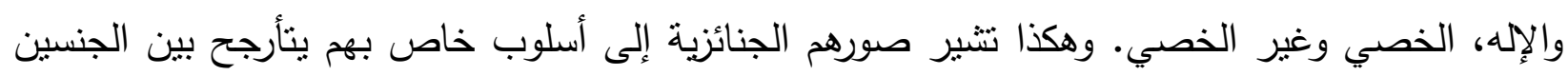
وكأنه تمثيل واضح لفكرة "الجنس الثالث".

${ }^{87}$ CALZA, Una Figura-ritratto di Archigallo Scoperta nella Necropoli del Portus Romae, , 227-31.

88 SANDERS, G.: « Gallos », RAC 8, 1972,.984-1034, 1020,1030. 


\section{ثبت المصادر والمراجع:}

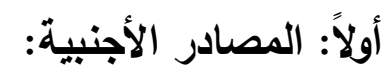

- Arnobius, Adversus Nationes, Translated by BryCE, A, H. T \& T. ClARK, 1871.

- Dionysius of Halicarnassus, Roman Antiquities, Translated by ERNEST CARY, Harvard University Press, 1937.

- Herodotus, translation by A. D. GodleY: Harvard University Press; London: W. Heinemann, 1920-25. Book I: 34-45.

- JUVENAL, Saturae, translated by RAMSAY. G., G. press 1918.

- Pausanias, Descriptions of Greece, Translated by Jones, W. H. S. \& OMERoD, H. A. Cambridge, MA, Harvard University Press; London, William Heinemann Ltd. 1918.

--virgil, translated by H. RUSHTON Fairclough, Loeb Classical Library. Harvard University Press: Cambridge, 1916.

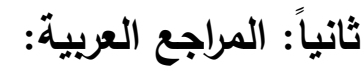

- ـ لازم، محمد، "الإلهة كيبيلي في الأسطورة والفن اليوناني والروماني"، بحث مقدم لنبل درجة الماجستبر في الآداب في الآثار

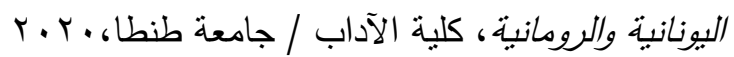

- LĀZĪM, MŪḤ̂AMMMĀD, «al-ilāh kībīlī fī al-usțūra wa'l-fan al-yūnānī wa'l-Rūmānī», Baḥt mūqadam lìnayl darğat al-Maǧistīr fì al-Adāb fì al-ațār al-yūnānìya wa'l-rūmānīya, Faculty of Arts / Tanta University, 2020.

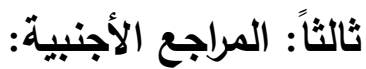

-Alans, S. \& SARMATIANS, Y. ,Some Notes on Parthian Costume Studies , Parthica, 15, 2013.

- ANTHONY C.: "Moral Appearance in Action: Effeminacy”, In his Controlling Laughter: Political Humor in the Late Roman Republic, Princeton, NJ: Princeton University Press, 1996.

- BARTMAN ,E.: « Hair and the Artifice of Roman Female Adornment », A JA 105, №. 1, Jan., 2001.

- BAlmer, J, Catullus: Poems of Love and Hate, Hexham: Bloodaxe, 2004.

- BEARD, M.: "The Roman and the Foreign: the Cult of the "Great Mother" In Imperial Rome" N. THOMAS \& C. HuMPHREY (eds.) Shamanism, History and the State, Ann Arbor, 1994.

- BORG, B., Mumienportrats: Chronologie und Kultureller Kontext, Mainz: von Zabern. 1996.

- BorgeA, P., La Mère des Dieux. De Cybèle à la Vierge Marie, Paris, 1996.

- Carcopino, J., Aspects Mystiques de la Rome Païenne, Paris, 1942.

-- CAlzA, G., Una Figura-ritratto di Archigallo Scoperta nella Necropoli del Portus Romae, Historia. Studi Storici per 1'Antichita Classica 6.

- Cumont, F.: «Le Taurobole et le Culte de Bellone», Revue d'Histoire et de Littérature Religieuses6, 1901.

- FitTschen, K., \& PAul. Z., Katalog der Römischen Portrats in den Capitolinischen Museen und den Anderen Kommunalen Sammlungen der Stadt Rom. Vol. 4: Kinderbildnisse. Nachträge zu den Bänden I-III. Neuzeitliche oder Neuzeitlich Verfalschte Bildnisse. Bildnisse an Reliefdenkmailern, Berlin: de Gruyter,2 014. -

- Françoise,V.,H. ,Rappresentazioni dei Ministri della Mater Magna a Roma e Nelle Province Occidentali dell'Impero, 2011,

- GASPARRO, S. G., Soteriology and Mystic Aspects in the Cult of Cybele and Attis, Amsterdam: Brill, 1985. 
-. GaZD. A., Elaine K., The Ancient Art of Emulation: Studies in Artistic Originality and Tradition from the Present to Classical Antiquity, 2012.

- GRANT, S.: “Criobolium”, In Chisholm, Hugh (edt.). Encyclopædia Britannica (11th d.). Cambridge University Press, 1911.

-- GOSE ,E.: "Bronze-statue Ue eines Attis aus der Mosel bei der Trierer RihnerlwUcke ", Trierer Zeitschrift 27, 1964.

- Hallett, J.: «Catullus and Horace on Roman Women Poets», Antichthon 40, Thematic issue: Catullus in Contemporary Perspective, 2006.

- Helbig, W.: « Fuihrer durch die Öffentlichen Sammlungen klassischer Altertümer ". In Rom, 2: Die Städtischen Sammlungen; Die Staatlichen Sammlungen», edited by HERMINE SPEIER. Tubingen: Wasmuth, 1966.

- JACOB, L.: «Fabulous Clap-Trap: Roman Masculinity», the Cult of Magna Mater, and Literary Constructions of the Galli at Rome from the Late Republic to Late Antiquity, The Journal of Religion , 92,. 1 January 2012,

- JAIME, A. E. J. A., «La Vulva de Atis», Arys, 17, 2019.

- LANCEllotTI, M.G., Attis: Between Myth and History: King, Priest, and God, Brill ,2002.

-- LeSley, A., Roy. A, Adkins Dictionary of Roman Religion, Oxford University Press, 1996.

- Marcus, T. V, Satires Ménippées. 4. Epitaphiones - Eumenides, édition JEAN-PIERre Cebe, Ecole Française de Rome, 1977.

-- Mekacher, N., Die Vestalischen Jungfrauen in der Römischen Kaiserzeit. Wiesbaden: Ludwig Reichert Verlag, 2006, 44-49.

- Rieger, AnNA-KatharinA: “Lokale Tradition versus Überregionale Einheit: Der Kult der Magna Mater." Mediterranea 4,2007.

- PHILIPPE B..: “Taurobo- Lion,” In Ansichten Griechischer Rituale: Geburtstags-Symposium fur Walter Burkert, Castelen bei Basel, 15. bis 18. Marz, 1996.,

- ROBERT, T., The Cults of the Roman Empire, The Great Mother and her Eunuchs , Wiley-Blackwell, 1996.

- RolleR, L. E.: « Attis on Greek Votive Monuments; Greek God or Phrygian? », Hesperia: 63 , 2., 1994 ,

- Roller, L.E..: “ The Cult of Anatolian Cybele ”:In Search of God the Mother, Berkeley, 1999.

- SANDERS, Gabriel. s.v. Gallos. RAC 8: 1972.

- SAWYER, D., Women and Religion in the First Christian Centuries, London \& New York, 1996.

-- SEIF EL-DiN, M.: «De la Société Royale d'Archéologie d'Alexandrie », Bulletin 46, Bronze Hoards from Sais:Sa el-Haggar, 2001.

- SieBert, A. V.: «Quellenanalytische Bemerkungen zu Haartracht und Kopfschmuck Römischer Priesterinnen», Boreas 18: 1995.

- SinN, F., Vatikanische Museen, Museo Gregoriano Profano ex Lateranense, Katalog der Skulpturen. Vol. 1, Die Grabdenkmaler 1: Reliefs, Altäre, Urnen, Monumenta Artis Romanae 17, Mainz: von Zabern, 1991.

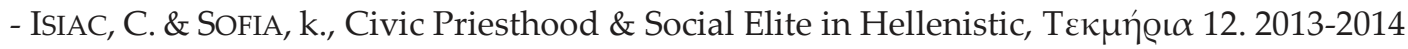

- TUnA, S., Dress and Identity in the Arts of Western Anatolia: The Seventh through Fourth Centuries BCE, Brunswick, New Jersey, 2011, 
-- TURCAN, R., The Cults of the Roman Empire, Oxford, 1996.

-VECIHI,Ö.:«The Shaft Monuments and the 'Taurobolium' among the Phrygians», Anatolian Studies47,1997.

- VERMASEREN, M.: «Legend of Attis in Greek and Roman Art», International Journal of Cambridge University Press, Leiden: E.J. Brill, 1966.

CCCA ,I, Asia Minor, BRILL, 1977.

, Corpus Cultus Cybelae Attidisque (CCCA) VII: Musea Et Collectiones Privatae, Brill, January 1, 1977.

Corpus Cultus Cybelae Attidisque (CCCA), V: Aegyptus, Africa, Hispania, Gallia Et Britannia, Brill, 1986.

Corpus Cultus Cybelae Attidisque: Germania, Raetia, Noricum, Pannonia, Dalmatia, Macedonia, Thracia, Moesia, Dacia, Regnum Bospori, Colchis, Scythia... Aux Religions Orientales Dans l'Empire, Brill August 1, 1997.

- WilSON. P.: «Cataractonium: Roman Catterick and its Hinterland», Inernational Journal of Research Rebort Series, 1958-1997. Parts I-II. York: Council for British Archaeology, 2002. 
الأثنكال والصور

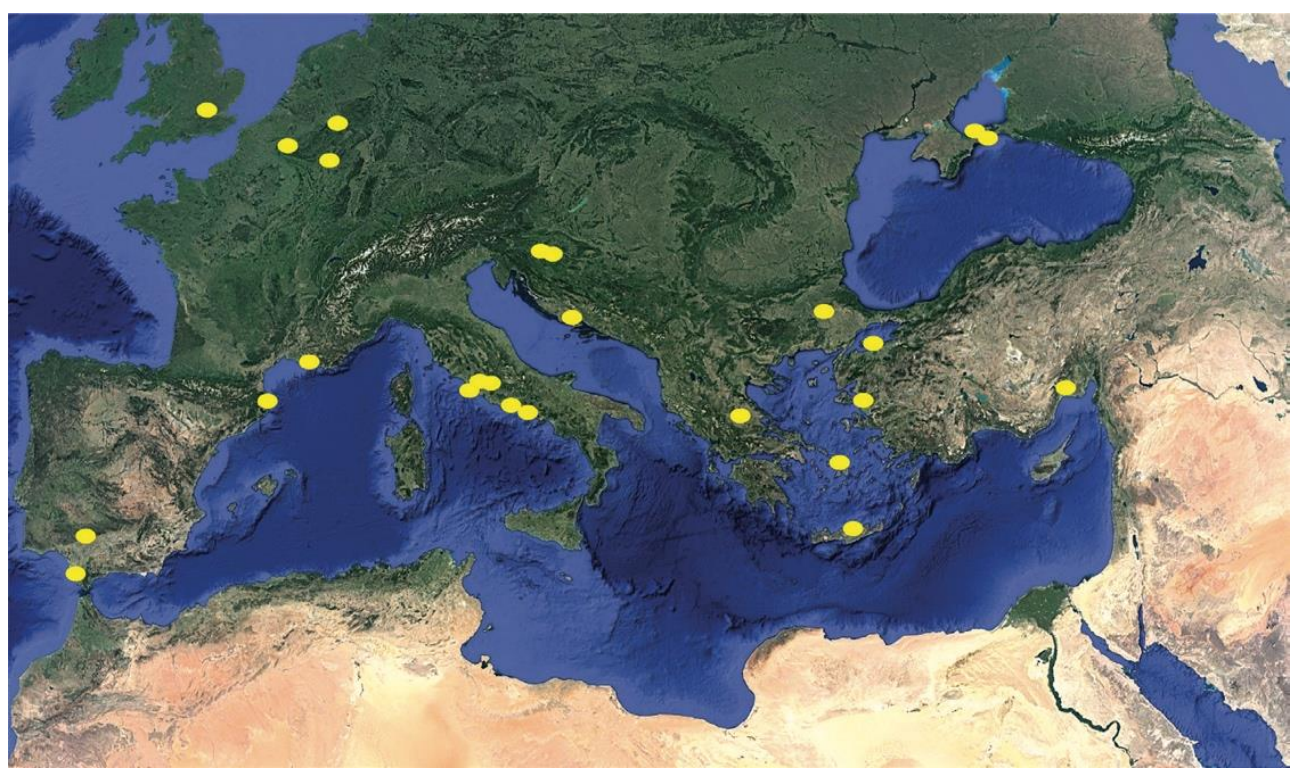

توضح أماكن العثور على تماثيل لأتيس (شكل ( ) )

JAIMe , La Vulva de Atis, 209.

$$
\text { اللوحات }
$$

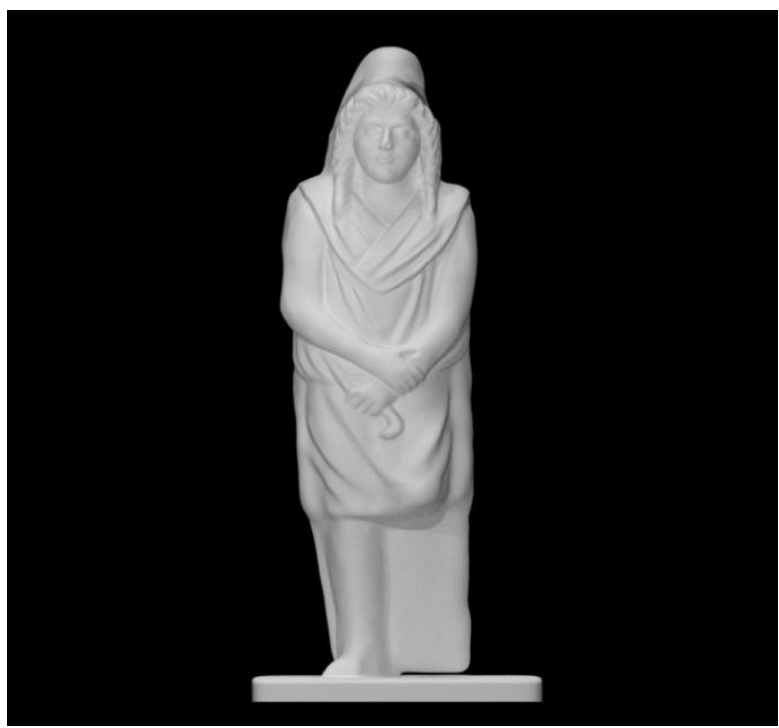

(صورة () أنتبس بتعبيرات حزينة

Museo Archeologico Nazionale di Napoli

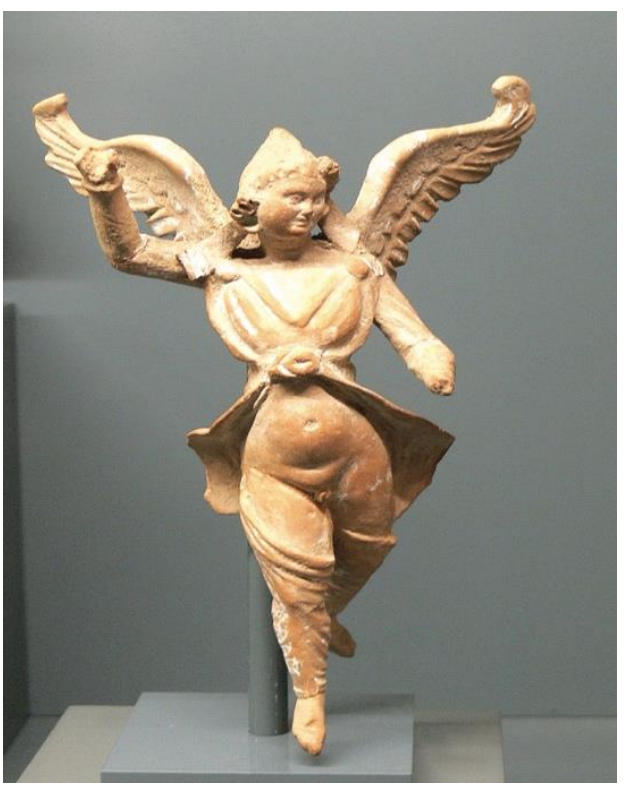

(صورة r) أتنيس مصورا بالأجنحة

https://commons.wikimedia.org/wiki/File: 21/3/2021PM - Attis.jpg.Access 


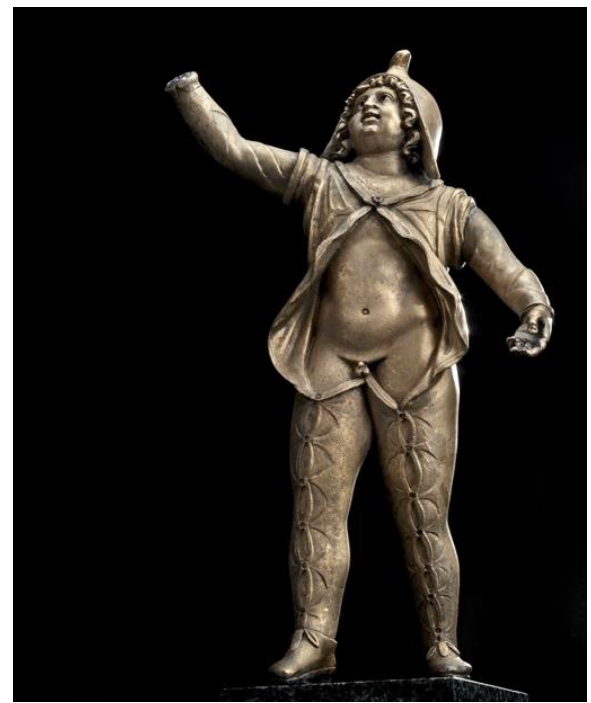

(صورة r) أنيس هيلاريا

https://rlp.museum-

digital.de/index.php?t=objekt\&oges $=3534$ Accessed 21/3/2021

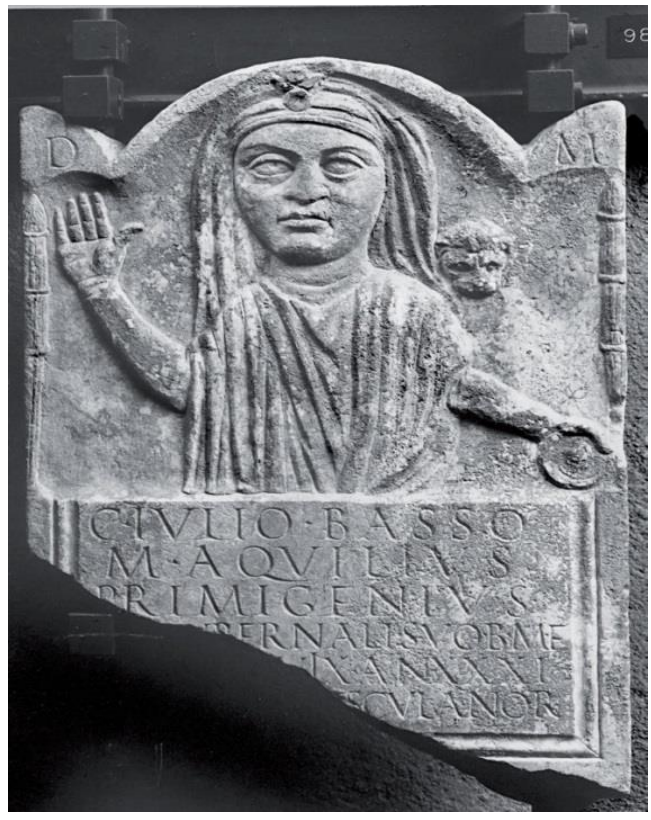

$$
\text { (صورة) شاهد قبر }
$$

Vatican, Museo Gregoriano Profano, Sez. 15 inv. no. 9826: http://arachne.uni-koeln.de/ item/marbilder/7247263 Accessed 21/32021.

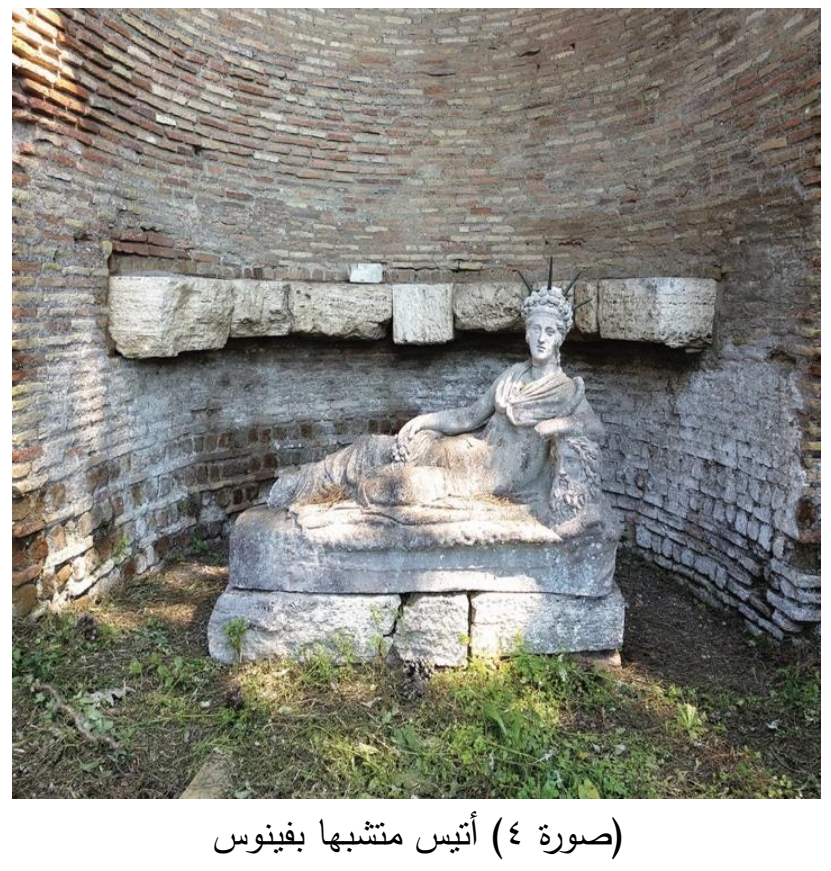

CCCA III, 123, № 394, CCXLIV. museo Laterano, no inv. 10785.

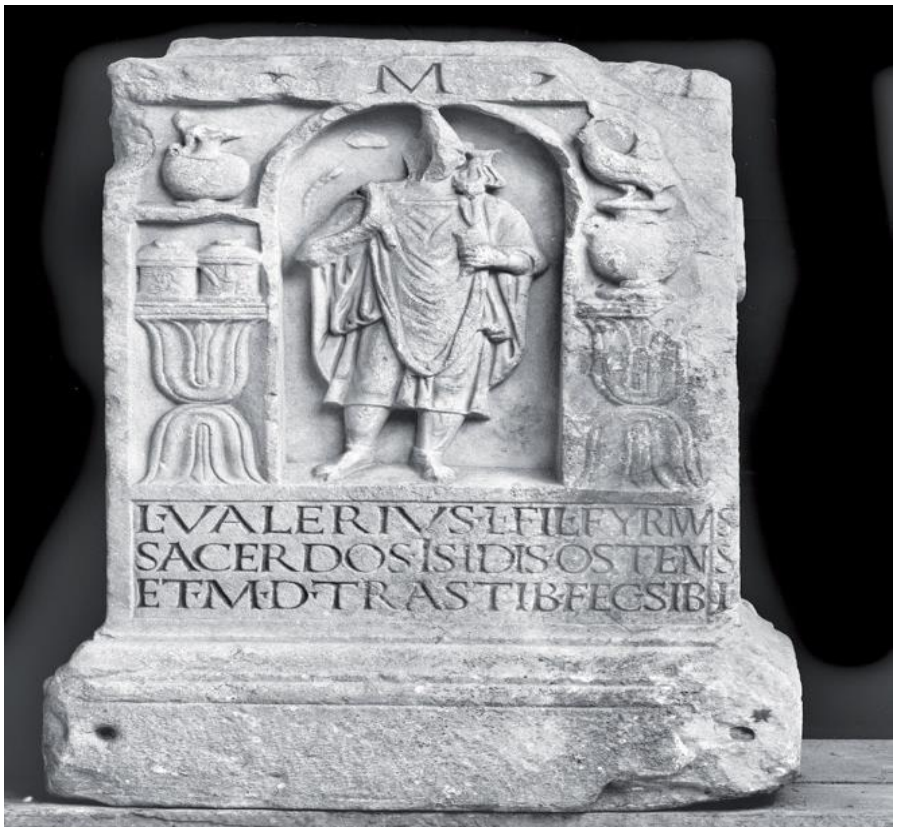

$$
\text { (صورة 0) شاهد قبر }
$$

Vatican, Museo Gregoriano Profano, Reparto di Ostia, inv. no. 10762: http://arachne.uni-

koeln.de/item/marbilder/6674791 Accessed 21/3/2021. 


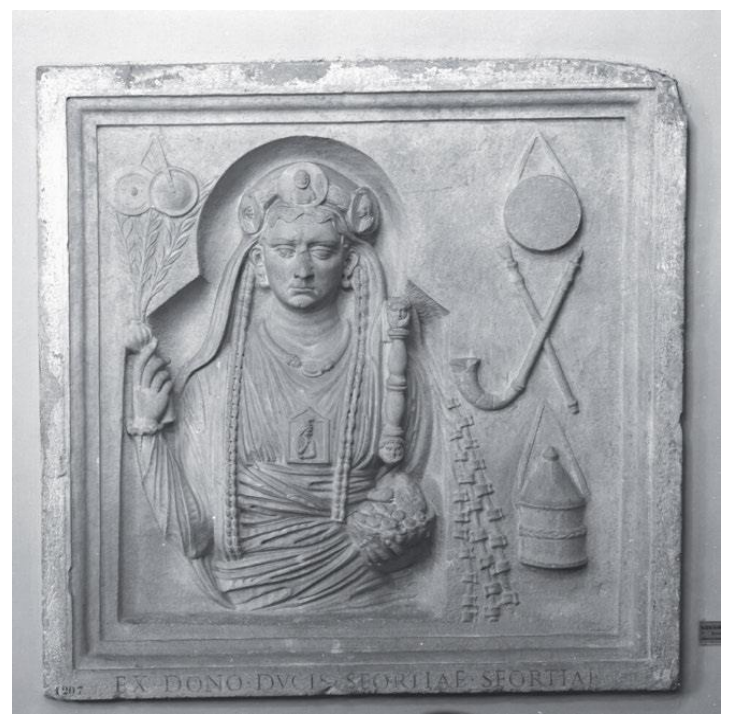

$$
\text { (صورة ^) كاهن بشرائط شعر }
$$

Rome, Musei Capitolini, Centrale

Montemartini inv. no. 1207:

http://arachne.uni-koeln. de/item/marbilder/667856 Accessed

$$
21 \backslash 3 \backslash 2021 .
$$

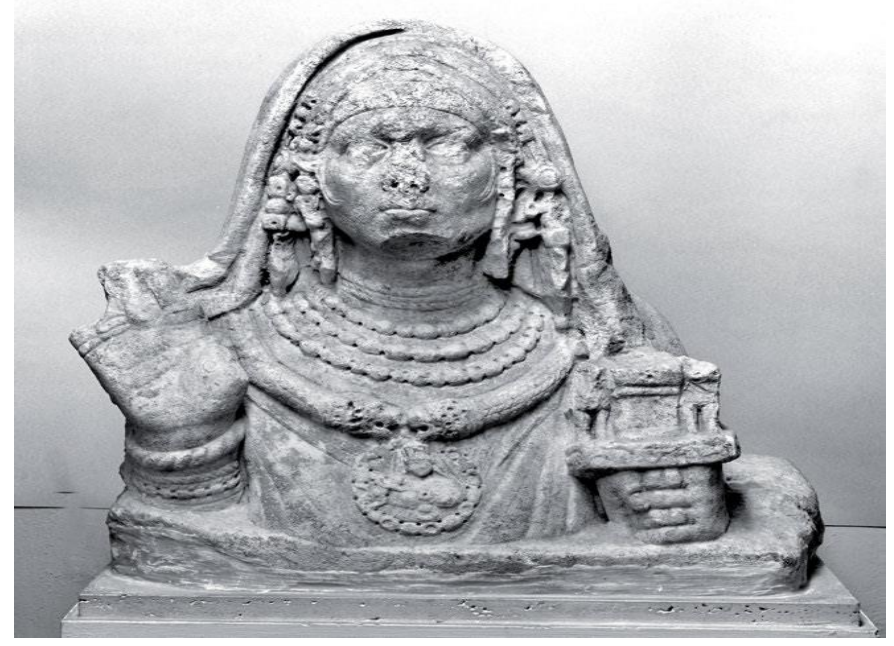

$$
\text { (صورة · ( ) تمثال لجذع كاهن }
$$

Rome, Musei Capitolini inv. no. 2971:

http://arachne.uni-koeln.de/item/marbilder/ 685615 Accessed 21/3/2021

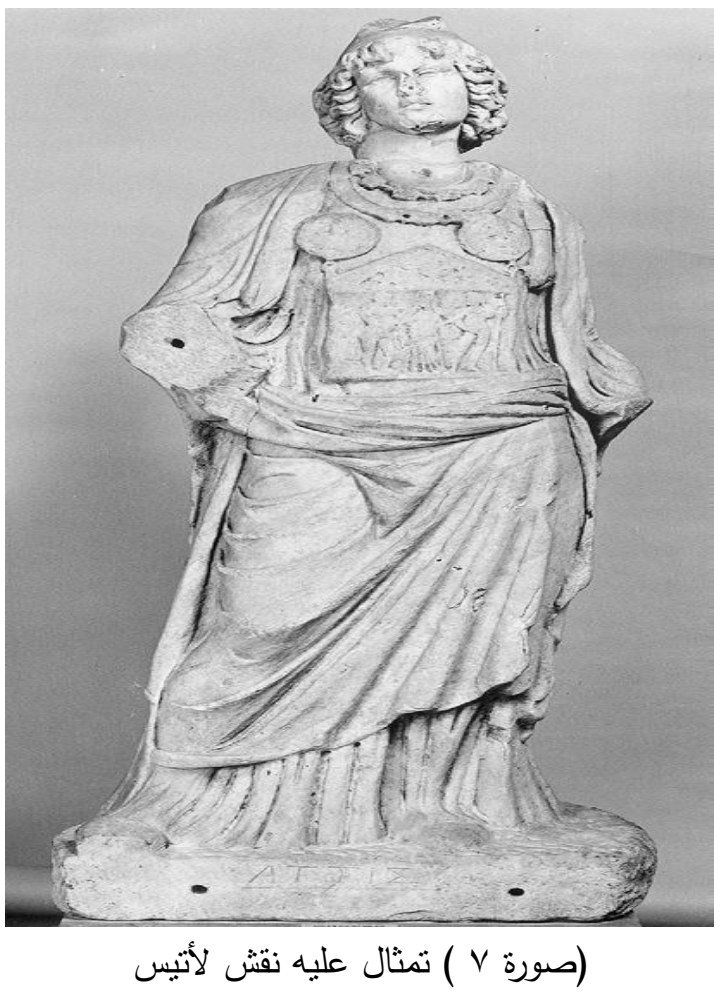

Rome, Musei Capitolini, Centrale Montemartini inv. no. MC 3047/S:

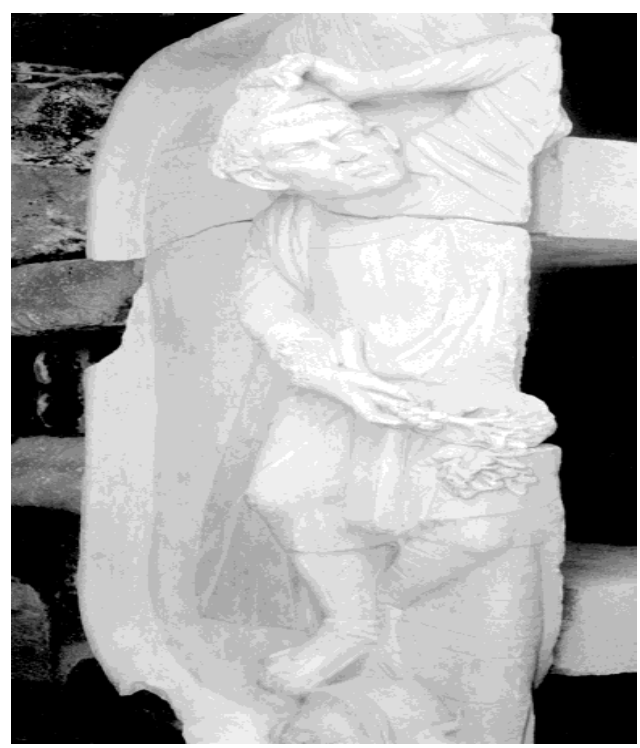

$$
\text { (صورة9 ) غطاء تابوت }
$$

Ostia, Museo Ostiense inv. no. 158: C. Faraglia (neg.), D-DAI-Rom-36.620. 


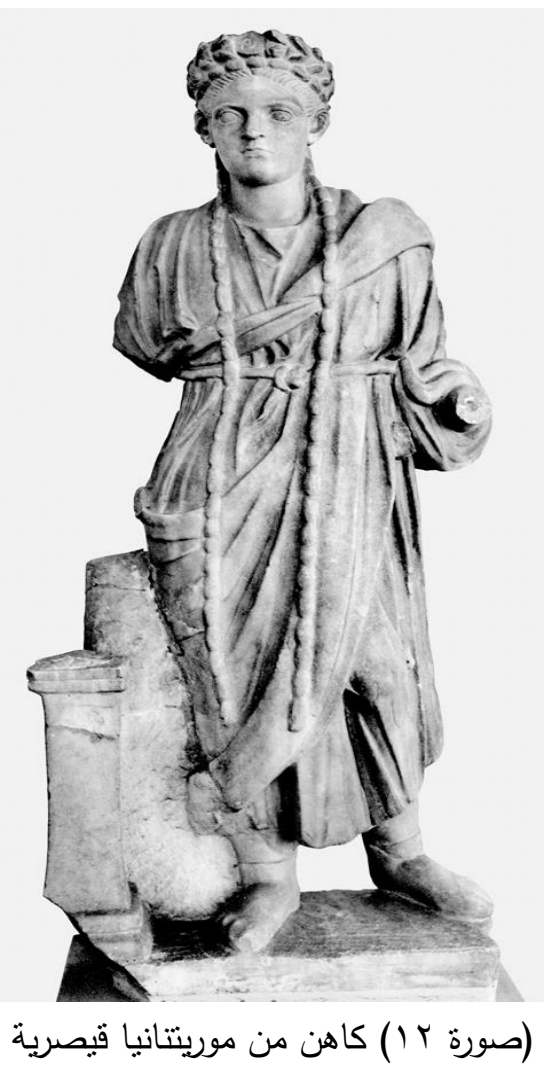

Cherchel, Museum: Photo Hans R. GoETte.

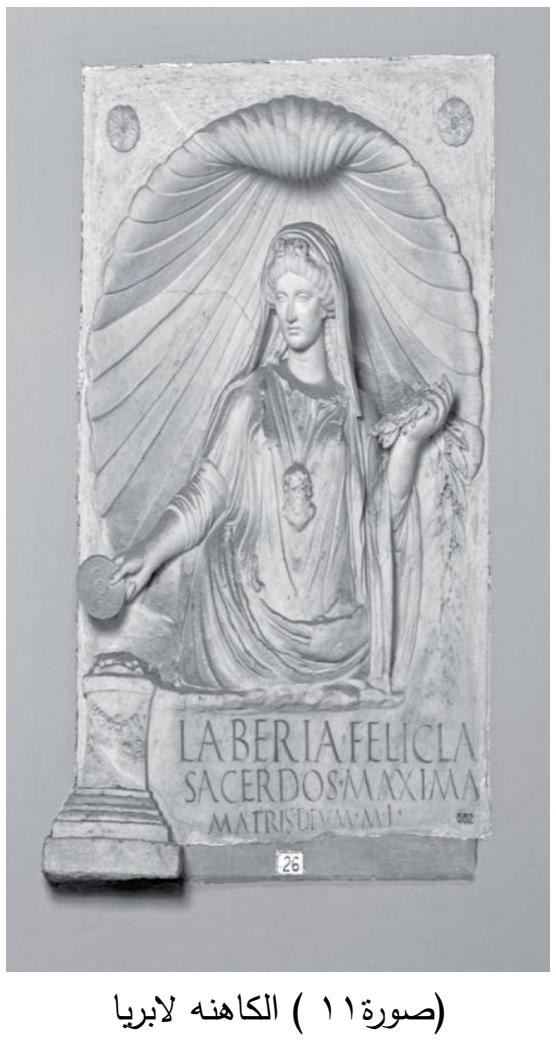

Vatican, Galleria. inv. no. 552: K. Anger (neg.), D-DAI-Rom-97Vat.679B. 